\title{
Quantification of soft soil cracking during suction cycles by image processing
}

Romain.Auvray@Univ-Lorraine.fr

Sandrine.Rosin@Univ-Lorraine.fr

Adel.Abdallah@Univ-Lorraine.fr

Farimah.Masrouri@Univ-Lorraine.fr

LEMTA-UMR 7563 CNRS, Université de Lorraine, rue M. Roubault, 54501 Vandoeuvre-lès-Nancy, FRANCE.

\section{ABSTRACT}

Soil cracking has been studied for many decades; however, it still deserves further investigation. This paper describes a new testing device that uses image processing to perform simultaneous and continuous quantification of the vertical strain and radial strain, crack area, and water content of a soil specimen subjected to suction cycles imposed by the vapour equilibrium method. An image processing method was designed to determine the crack area and the soil radial strain separately. The evolution of each measured parameter over time in a clayey soil specimen subjected to 3 suction cycles is presented and discussed. The first suction cycle has the greatest impact on the crack area, the mass water content, the vertical strains and the radial strains. Hysteresis loops were observed for crack area and radial strain evolution.

Keywords : Soft Soil - Suction Cycles - Crack - Shrinkage - Image Processing.

\section{Introduction}

Soils with a significant proportion of swelling clays are very sensitive to variation in water content (Hillel, 1988). Swelling occurs when the water content increases, while shrinking occurs when the water content decreases. Non-uniform settlements in the soil under buildings and in soil subject to air desiccation can damage building foundations (e.g., 
Nelson and Miller., 1992; Maisa et al., 2004; Abdelmalak., 2007; Jahangir et al., 2011; Jahangir et al. 2012). Moreover, drying increases tensile stresses that can locally exceed the soil's tensile strength, which leads to the initiation of cracks (Konrad and Ayad, 1997). Cracks can increase the hydraulic conductivity of soil by 1 to 3 orders of magnitude (Phifer et al., 1994; Omidi et al., 1995; Drumm et al., 1997; Miller et al., 1998; Yuen et al., 1998; Yesiller et al., 2000; Albrecht et al., 2001; Tay et al., 2001, Rayhani et al., 2007; Sadek et al., 2007). Cracks influence the swelling and shrinking of soils because they allow deeper layers to be subjected to hydric variation. Cracks also decrease the bearing capacity of soil and constitute points of weakness that may affect the stability and the integrity of geotechnical structures. To prevent such effects, a better understanding of the swelling/shrinkage phenomenon and the initialisation, propagation and impact of cracks on soil parameters is needed. To achieve this objective, an accurate method for quantifying shrinkage and crack intensities under suction-controlled conditions is needed.

Studies of volumetric shrinkage initiation and its effects on soil properties have typically been conducted using uncracked soil samples. Under field conditions, some authors have studied the relationship between the appearance of cracks and vertical volumetric shrinkage (Kleppe and Olsen, 1981, Hewitt and Philip, 1999; Velde, 1999; Elias et al., 2001). Kleppe and Olsen (1981) showed that cracks appear in a sand-bentonite mixture when its volumetric shrinkage exceeds $10 \%$. However, for some other soils, cracks may occur when the volumetric shrinkage reaches $5 \%$ (Tay et al., 2001). A similar correlation was observed under laboratory conditions, not only with vertical but also with horizontal shrinkage (Lloret et al., 1998; Peng et al., 2006; Péron et al., 2009). Horizontal shrinkage typically occurs at the interface between the soil and the cell wall. Some authors have studied the volumetric changes of soil undergoing desiccation and have concluded that volumetric shrinkage increases with increasing clay content and the initial water content (Bronswijk, 1991; Hallaire, 1991; Kleppe and Olsen, 1981; Tariq et al., 1993; Tay et al., 2001; Boivin et al., 2004). 
under intensively dry conditions, whereas during rainy periods, crack depth and width tend to decrease, and cracks can close completely. This is known as the self-healing phenomenon (Edgenbrod, 2003). Self-healing may not be complete in all cases, and can be limited to the soil surface, which can potentially lead to water being trapped and pore pressure increasing (Mallwitz, 1998). An important aspect of the study of soil cracking is quantifying crack pattern characteristics to determine the influence of material properties, humidity and air temperature on cracks. Some researchers have already identified some trends. Wider cracks and a denser crack pattern were obtained for soils with a higher proportion of clay (Kleppe and Olsen, 1985; Tay et al., 2001; Elias et al., 2001; Edgenbrood et al., 2003; Boivin et al., 2004; Rayhani et al., 2007), a higher air temperature (Tang et al., 2010; Rayhani et al. 2007) and a higher initial moisture content (Tay et al., 2001; Tang et al., 2010). Similarly, a higher initial thickness of laboratory specimens resulted in more widely spaced cracks (Lloret et al., 1998; Rodriguez et al., 2007; Atique and Sanchez, 2011).

Some image-based experimental devices have been developed to quantify, with sufficient accuracy, crack development as a function of soil characteristics and environmental conditions (Miller et al., 1998; Yesiller et al., 2000; Velde, 2001; Tay et al., 2001; Peng et al., 2006; Lasmikantha et al., 2009; Tang et al., 2010; Atique and Sanchez 2011). These imagebased devices typically employ an image processing method to determine the crack intensity factor (CIF) (Miller et al., 1998; Vogel et al., 2005; Peng et al., 2006, Larshmikantha et al., 2009; Tang et al., 2010; Atique and Sanchez., 2011). The CIF was defined by Miller et al. (1998) as the ratio between the crack area and the entire specimen surface area. The evolution of the CIF was usually quantified using initially saturated soils subjected to air drying or oven drying. These conditions lead to large cracks that are easily identifiable on the specimen surface. However, air drying and oven drying do not allow control of the suction of the specimen, defined as the water potential in a soil-vapour system (Richards, 1975), and the saturated initial state may not be comparable to the natural state. 
However, some researchers have combined the cracking surface and the shrinkage surface into a single CIF value referred to as $\mathrm{CIF}_{\text {tot }}$ (Peng et al., 2006). Others have concentrated their studies on cracks occurring on the inner surface of the specimen, leading to the definition of another factor, referred to here as CIF* (e.g., Miller et al., 1998; Yesiller et al., 2000; Laskmikantha et al., 2009; Tang et al., 2010). As a result, methods are available to quantify separately the crack surface or the shrinkage surface, but to our knowledge, no automatic method has yet been proposed to quantify the two surfaces for the same sample. This coupled quantification is needed to acquire a complete understanding of the influence of drying on cracking.

The present study seeks to quantify the evolution of CIF and volumetric shrinkage in a clayey specimen submitted to suction-controlled drying-wetting cycles at a constant temperature of $20^{\circ} \mathrm{C}$. The initial water content and dry density of the specimen were selected within the range corresponding to a natural soil in a temperate climate. The material and the experimental setup are presented in the first part of this paper. To quantify the cracks and the shrinkage intensities in the specimen, an image processing method was developed and is described in the second part of this paper. The method includes an algorithm to evaluate the horizontal shrinkage. The image processing method was tested on calibrated real images. The third part of this paper describes the application of the image processing method to a sequence of 3,000 images obtained during the imposition of 3 successive suction cycles to the specimen. The paper concludes with a discussion of the potential uses of the image processing method developed and the impact of suction cycles on cracks and shrinkage intensities in soils. 
A mixture of a bentonite and a natural silt from Xeuilley (in northeast France) was used in this study. The mixture contains $40 \%$ Xeuilley silt and $60 \%$ bentonite by weight. The materials were initially dried and sieved to $400 \mu \mathrm{m}$ and then mixed together. The basic characteristics of the materials and the mixture are summarised in Table 1.

\subsection{Soil preparation}

The soil was mixed with distilled water to reach a water content of $15.5 \%$ and cured for $24 \mathrm{~h}$ under plastic wrap to homogenise the water content. The mixture was then sieved to $4 \mathrm{~mm}$ to remove the largest aggregates. Such aggregates could influence desiccation by creating preferential paths for drying in the inter-aggregate space, which in turn could influence the development of cracking (Nowamooz and Masrouri, 2008). The measured water content after sieving was $15.3 \%$. The 20 -mm-tall specimen was prepared, by static compaction, in two layers in a stainless steel circular cell $102 \mathrm{~mm}$ in diameter and $60 \mathrm{~mm}$ in height to reach a final dry density of $1.27 \mathrm{Mg} / \mathrm{m}^{3}$. The base of the cell is grooved to ensure good adhesion between the soil and the cell.

\subsection{Experimental setup}

The specimen was placed in a hermetic container (Fig. 1) and exposed to 3 drying-wetting cycles. These cycles were imposed using the vapour equilibrium method (Lide et al., 2002; Blatz et al., 2008; ISO, 1999). This method consists of putting a specimen into a container that includes a salt solution. The soil sample absorbs or desorbs water vapour until the potential equilibrium is reached. The imposition of a given relative humidity $(R H)$ on a soil sample allows its suction to be controlled according to the Kelvin equation:

$$
s=-\gamma_{w} * \frac{R T}{M g} \ln (R H)
$$

[Equation 1] 
where, $s$ is pore negative air pressure or suction $(\mathrm{kPa}), \mathrm{R}$ is universal constant for perfect gases $\left(8.31 \mathrm{~J}^{-1} \mathrm{~mol}^{-1} \mathrm{~K}^{-1}\right), \gamma_{\mathrm{w}}$ is the unit weight of water $\left(9.81 \mathrm{kN} \mathrm{m}^{-3}\right), \mathrm{g}$ is the gravitational constant $\left(9.8 \mathrm{~m} \mathrm{~s}^{-2}\right), \mathrm{M}$ is molecular weight of water $\left(18 \cdot 10^{-3} \mathrm{~kg} \mathrm{~mol}^{-1}\right)$ and $\mathrm{RH}$ is relative humidity (\%). This method is influenced by a number of parameters, such as the type of salt solution, pressure and temperature. Here to limit the influence of temperature, salts less sensitive to temperature were selected.

The humidity and temperature in the container were measured continuously during the test to control the applied suction. The suction target value is reached after a period of 5 to 24 hours with $5 \%$ accuracy. The laboratory atmosphere was air-conditioned at $20^{\circ} \mathrm{C}$.

During the test, the specimen was weighed continuously to measure the evolution of the water content of the specimen. The specimen's height variations were measured with an accuracy of $0.01 \mathrm{~mm}$ using a laser distance sensor fixed on a sliding pane. Nine measurements, spaced at $10 \pm 0.01 \mathrm{~mm}$, were taken every day along a diameter line of the specimen.

To study the surface cracks and shrinkage of the specimen at the same time, a precise camera positioned $350 \mathrm{~mm}$ from the surface of the specimen took photographs every 30 minutes. Because each cycle provides 1,000 images to be analysed, an automatic image processing method is needed.

\subsection{Description of calibration images}

To test the performance of the different steps of image processing method allowing the determination of the crack and the shrinkage intensities, two specimens images, named images of calibrations, with inherent cracks are considered (Fig 2). Their crack and shrinkage areas were calculated precisely. Calibration image $n^{\circ 1}$ (Fig. 2a) was obtained with the experimental device; it corresponds to the image of the cracked surface of a specimen after desiccation under a suction of $113 \mathrm{MPa}$ for 21 days. This image shows large cracks and a 
large shrinkage area. Calibration image $\mathrm{n}^{\circ} 2$ (Fig. 2c) was obtained with the experimental device and corresponds to the image of the cracked surface of a specimen after desiccation under a suction of $113 \mathrm{MPa}$ for 7 days. This image shows narrow cracks and a narrow shrinkage area. The exact areas of the cracks and shrinkage were determined with ImageJ, a public-domain software for image processing (Rosband 2006), by manually marking the shrinkage area $\left(\mathrm{S}_{\mathrm{ref}}\right)$ and the crack area $\left(\mathrm{C}_{\mathrm{ref}}\right)$ using a method similar to the one used by Peng et al. (2006) (fig. 2b). Peng et al. (2006) used the "magic wand" tool in Adobe Photoshop 7, which separated cracks from the surface of the soil. In this study, the manual determination of the cracks and shrinkage area was done using the "pencil" tool in ImageJ, which allows the operator to manually fill the cracks or shrinkage areas. For calibration images $n^{\circ} 1$ and $n^{\circ} 2$, respectively, this method yielded a shrinkage area $\left(S_{\text {ref1 }}\right)$ of $147600 p x$ and a crack surface $\left(\mathrm{C}_{\text {ref1 }}\right)$ of $34565 \mathrm{px}$, and a shrinkage area $\left(\mathrm{S}_{\text {ret2 }}\right)$ of $50476 \mathrm{px}$ and a crack surface $\left(\mathrm{C}_{\text {ret2 }}\right)$ of $16273 \mathrm{px}$. This method is accurate but highly time-consuming and cannot be used to process the 3,000 images captured during one test.

\section{Image processing method}

An automatic image processing method was developed to handle each image of a test, to quantify the evolution of cracks and shrinkage areas in a specimen surface over time. The method was programmed as an ImageJ plugin. This section presents the steps of the image processing method, illustrated in the chart given in Fig. 3. To calibrate the method, the image processing results for calibration images $n^{\circ} 1$ and $n^{\circ} 2$ were analysed and are presented in section 3.3.3. The results from each step of the image processing method for calibration image $n^{\circ} 1$ are given in Fig. 4. The implementation of this method in programmed ImageJ plugins permitted automated processing of a sequence of 3,000 images, which is presented and discussed in section 4.

\subsection{Preparation of the raw images}


178 The raw calibration image is an uncentred RGB (red green blue) image (Fig. 4a). The 179 preparation of the image for processing consists of converting the image to a greyscale image and selecting the circular surface of the specimen to create a centred greyscale image with a white background. This is referred to as the prepared image (Fig. 4b). The contour line of the specimen surface is referred to as $C_{\text {ext }}$. It was determined manually for the first image and then computed in the plugin. The RGB image is converted in gray-scale image by using a method proposed by Lakshmikantha et al. (2009).

\subsection{Filtering of the prepared image}

The prepared image preserves the defaults of the raw image, such as the uneven illumination of the specimen's surface and texture artefacts. To correct the image illumination, some authors such as Lakshmikantha et al. (2009) have used an ImageJ function called subtract background. This tool removes smooth continuous backgrounds using a rolling ball algorithm (Sternberg, 1983). The rolling ball radius has to be at least as large as the radius of the largest object in the image that is not a part of the background. However, the area of the elements of the cracks or the shrinkage surface changes over time during the test. Moreover, the size of the cracks and the size of the elements of the shrinkage area are quite different, and this difference also changes during the drying and wetting stages. These two facts make the definition of the required rolling ball radius for each image quite impossible.

To correct the uneven illumination and the deformation of the specimen during the drying, Vogel et al. (2005) used a local threshold and compare the crack detection of the successive images. Base on this concept, the surface of our prepared image was filter by a reference filter. The reference filter is applied to each prepared image of the sequence by addition. The resulting image, referred to as the corrected image (Fig. 4c), represents only the difference between the initial specimen surface image and the current specimen image. Consequently, the uneven illumination of the specimen is corrected assuming constant lighting during the 
test. This method can be applied to images without consideration of their scale, size, shape and the nature of the soil. The reference filter is prepared manually before the image analysis process begins and must be changed for each test.

Because the aim of the image processing method is to determine the shrinkage area and the inner crack area independently, the image processing method was then divided into two parts. The first part determines the shrinkage area and the second part determines the inner crack area.

\subsection{Determination of the shrinkage area}

\subsubsection{Segmentation of the corrected image}

The corrected image is a greyscale image. To differentiate the cracks and the shrinkage area from intact soil, an image segmentation is needed. The segmentation divides the digital image into multiple regions, according to a chosen criterion, for example, a threshold. In this study, the threshold is the greyscale value that defines the limit between the cracks and the shrinkage area (the darker pixels), and the intact soil (the brighter pixels). The segmentation consists of comparing each pixel of the greyscale image to the threshold. If the pixel is darker than the threshold, its value becomes 0 (a black pixel); otherwise, its value becomes 255 (a spurious white pixel). As a result, the corrected image becomes a binary image, called a segmented image (Fig. 4d). The choice of the final threshold ImageJ function used to determine the shrinkage area is described in section 3.3.3. The choice is based on a comparison of the results obtained from the complete image processing method with different threshold functions applied to the calibration images.

After the segmentation, some white points appear in the shrinkage area and may lead to an underestimation of its surface area. Some binary operators can improve the accuracy by filling these white points (Serra, 1982). The Dilate operator switches a pixel black if all of the pixels nearby are black, whereas the Erode operator switches a pixel to white if all of the pixels nearby are white. The Close operator is a combination of the Dilate operator and the 
Erode operator. This operator makes it possible to fill the holes in the shrinkage area.

Various combinations of binary operators such as Erode, Dilate, Open and Close were tested on the calibration images to fill the white points present in the shrinkage area. The Close operator succeeded in improving the shrinkage area quantification. After the application of the binary operator Close, the segmented image results in the final image (Fig. 4e).

\subsubsection{Application of the Diameter algorithm}

To determine the shrinkage area, an ImageJ plugin was developed in JavaScript during this study. This algorithm, called the "diameter algorithm", seeks to determine the area between the cell wall and the border of the specimen. The specimen border is difficult to determine because it changes with the swelling or shrinkage of the specimen. The diameter algorithm considers several diameter lines spaced one degree apart. Each diameter intersects the cell at two points, $A_{c}$ and $B_{c}$, and the border of the specimen at another two points, $A_{s}$ and $B_{s}$ (Fig. 5). The shrinkage area corresponds to the number of pixels between $A_{c}$ and $A_{s}$ and between $B_{c}$ and $B_{s}$. The algorithm counts the number of black pixels starting at $A_{c}$ until it encounters 5 consecutive white pixels. As a result, the black pixels corresponding to the cracks are not counted. This value of 5 pixels allows the algorithm to keep counting even if white points are still present in the shrinkage surface. Because the specimen radial deformation may not be perfectly axisymmetric, a sufficient number of diameters have to be determined. Fig. 6 shows the evolution of the relative error between the shrinkage area calculated with the diameter algorithm and the $\mathrm{S}_{\text {ref }}$ according to the number of diameters considered. The curve shows that considering at least 180 diameters leads to an accurate determination of the shrinkage area. The higher the number of diameters considered, the more accurate and the more time-consuming the calculation. As a consequence, 180 was chosen as the number of diameters needed.

The shrinkage area was then determined, presuming that the shrinkage is constant along an arc of a circle of 0.5 degrees around each extremity of the diameter. The mean values of the 
radial shrinkage as well as the maximum value of the horizontal shrinkage are also determined. Given the value of radial shrinkage, the value of the radial strains can be calculated from the diameter algorithm.

\subsubsection{Choice of the threshold function}

Various threshold functions are implemented in ImageJ and are easily accessible through the ImageJ Interface (see Table 2). In the following section, we present the selection of the function for threshold determination.

\subsubsection{Determination of the threshold function}

Because the image processing method seeks to quantify the shrinkage area and cracks of a specimen, it has to be efficient for both large and small cracks and shrinkage areas. The quantification of a large shrinkage area is easier because the pixels corresponding to a large area are darker and more numerous than those corresponding to a smaller area. The pixels of a large shrinkage area have a greater influence on the greyscale histogram, which results in easier determination of the threshold value. As a consequence, a threshold function that is efficient in quantifying a large shrinkage area might not be accurate enough to quantify a small shrinkage area.

On the basis of these observations, a two-step method for choosing the threshold ImageJ function was defined. The first step consisted of applying different threshold ImageJ functions to calibrate image $n^{\circ} 1$, which contains quite large cracks and a large shrinkage area (Fig. 2a). A comparison of the different results with the manually determined values, $S_{\text {ref } 1}$, is presented in section 2.3. The ImageJ threshold functions that yielded a value for the shrinkage area close to $10 \%$ of $S_{\text {ref } 1}$ were selected. The second step consisted of applying the selected threshold ImageJ function to calibrate image $\mathrm{n}^{\circ} 2$, which contains quite small cracks and a small shrinkage area (Fig. 2c). A comparison of the different results with the manually determined values, $S_{\text {ref2, }}$ is presented in section 3.3. 
282

Table 3 presents the shrinkage areas and their relative error obtained using different ImageJ threshold functions for calibration image $n^{\circ} 1$. The results are compared to $S_{\text {ref1 }}$. The results for the Li, MinError and Shanbag threshold ImageJ functions are not presented in Table 3 because they were not able to detect shrinkage elements. The low contrast of the corrected image (Fig. 4c) made the use of the Triangle, Huang, Intermodes, Mean, Minimum and Percentile threshold ImageJ functions inefficient. Other threshold ImageJ functions, namely Otsu, IsoData, IJ_isodata, Moment, Max_Entropy, Yen and RenyiEntropy, yielded an accurate estimation of the shrinkage area for calibration image $n^{\circ} 1$. These threshold ImageJ functions were then applied to calibration image $n^{\circ} 2$ (Table 4). The Otsu, IsoData, IJ_isodata and Moment threshold ImageJ functions yielded an inaccurate quantification of the shrinkage for calibration image $n^{\circ} 2$. Thus, these functions were not chosen. The 3 remaining threshold ImageJ functions, named Yen, RenyiEntropy and Max_Entropy, yielded correct estimations of the shrinkage area for both calibration images. These 3 functions have the same basis: an element is detected if its greyscale level presents a large difference from those of neighbouring elements. These functions also provide the same accuracy (Table 2, Table 3). We present herein the results obtained with the Max_Entropy function.

\subsection{Determination of the crack area}

To improve crack detection, a ring with a width equal to the maximum value of horizontal shrinkage was deleted from the corrected image (Fig. 4c) to remove the entire shrinkage area. The resulting image is called the reduced corrected image (Fig. 4f). The efficiency of the different threshold ImageJ functions was compared to $\mathrm{C}_{\text {ref1 }}$ and $\mathrm{C}_{\text {ref2 }}$, which are the values of the crack area for calibration images $n^{\circ} 1$ and $n^{\circ} 2$, respectively, determined as described in section 2.3. The Max_Entropy function was selected and applied to the reduced corrected image (Fig. 4g). Lakmikantha et al. (2009) proposed the use of a Despeckle median filter that replaces each pixel with the median value (white or black) of the pixels in its immediate 
vicinity. This filter is considered to be efficient in reducing the noise in binary pictures. Therefore, a combination of the Despeckle median filter and the Close operator was applied to the image to delete elements of the remaining noise and to fill crack elements (Fig. 4h).

The analyze particle command was then used to calculate the number of black pixels in the reduced binary image, which corresponds to the crack area.

This value is computed and divided by the area of the reduced specimen to obtain $\mathrm{CIF}^{*}$ (Equation 5). The sum of the crack area and the shrinkage area is divided by the initial specimen area to determine the $\mathrm{CIF}_{\text {tot }}$ (Equation 6).

$$
\begin{aligned}
& C I F^{*}=\frac{\text { Crack area }}{\text { Reduced specimen area }} * 100 \\
& C I F_{\text {tot }}=\frac{\text { Crack area }+ \text { Shrinkage area }}{\text { Initial specimen area }} * 100
\end{aligned}
$$

\section{Application of the procedure to a complete test}

The calibrated image processing method was applied to a complete drying/wetting test of the previously described silt-bentonite specimen. The test included 3 suction cycles ranging from 20.5 MPa to $113 \mathrm{MPa}$, corresponding to air relative humidities of $86 \%$ and $46 \%$, respectively. Each cycle comprises one drying phase and one wetting phase. Fig. 7a illustrates the evolution of the imposed suction over time and shows that the water content reaches equilibrium almost 20 days after the imposition of suction.

\subsection{Hysteresis and evolution of measured parameters}

Fig. $7 \mathrm{~b}$ and $7 \mathrm{c}$ present the evolution of the mass water content and vertical strain, respectively, with time, and Fig. 8 shows the evolution of the vertical strain with mass water content. The vertical strain value is calculated using the height of the specimen obtained by averaging the nine measurements obtained by the laser sensor. The first drying phase 
appears to have the greatest influence because the variation of the different parameters is more significant during the first drying stage than during the later drying stages. The first drying/wetting cycle showed, for imposed suctions of similar magnitude, significant hysteresis of the water content (from $15.3 \%$ to $10.5 \%$ ) and of the vertical strains (from 0 to $1 \%$ ). No more irreversible variation could be observed at the end of several subsequent cycles. Indeed, the soil seems to exhibit elastic reversible behaviour after the first drying/wetting cycle associated with the reduction of the range of water content variation and the development of unrecoverable vertical deformation (Fig. 8).

\subsection{Description of crack patterns}

The figure 9 presents the surface specimen at different moment of the first phase of drying. To improve the specimen cracks observation the contrast of figure $9 \mathrm{~b}$ to $9 \mathrm{~h}$ was increased. Early in the first drying phase, numerous tiny cracks appear homogeneously distributed on the soil surface (Fig. 9a, 9b, 9c, 9d). With further desiccation, some of these cracks grow in a preferential manner, whereas others tend to close (Fig. 9e, 9f, 9g, 9h). The remaining observed cracks have a radial orientation, and their angles of intersection are $90^{\circ}, 60^{\circ}$ and $120^{\circ} \mathrm{C}$. Radial shrinkage can be observed to occur simultaneously with the growth of the main cracks.

Fig. 10 presents images of the specimen surface at successive wetting/drying phases (Fig. 10a corresponds to Fig. 9a, and Fig. 10b corresponds to Fig. 9h). After the first wetting phase, partial self-healing occurs, and some of the main cracks remain open (Fig. 9). During the next drying phase, the remaining unclosed cracks form preferential desiccation zones from which cracking propagates, following the previous pattern, and no new cracks appear (Fig. 10d). Subsequent wetting/drying cycles produce the same trends (Fig. 10f).

\subsection{Radial shrinkage and CIF evolution}

The image processing method was applied to the images of the previously presented test to estimate the radial strains during the cycles (Fig. 11, Fig. 12). This facilitated the comparison of the evolution of the shrinkage area and the inner crack area (Fig. 13).The amplitude of the shrinking area appears to be of the same order of magnitude as the inner crack area and appears to follow a similar evolution. Significant hysteresis was observed after the first 
drying-wetting cycle, while a reversible trend was noticed during the second and the third cycles.

The evolution of the radial strains and the $\mathrm{CIF}^{*}$ versus the vertical strain are shown in Fig. $14 \mathrm{a}$ and Fig. 14b, respectively. The evolution of the two parameters is similar. Indeed, neither shrinking nor cracking is observed until the vertical strain reaches a value of $0.3 \%$. The evolution is then very slow and quasi-linear until the vertical strain reaches a value of $0.6 \%$. Then, the variation becomes sharper. After subsequent drying/wetting cycles, the irreversible (plastic) radial strain reaches $1 \%$. A difference between the wetting path and the drying path is clearly observed for the two parameters, forming hysteresis loops, although these loops are narrower for the radial strain than they are for the CIF*. For the first drying phase the $\mathrm{CIF}^{*}$ seems to be links with radial stains by a linear relation (fig. 14c) and. the cracks and the radial stains seems to initiate in the same time. A difference is observed in the drying and wetting paths for the different cycles. The drying path of the second and the third cycle (respectively the wetting phase) are the same.

\section{DISCUSSION}

Using the method described in this paper, the influence of suction cycles on cracking in soils has been studied with an accuracy of within $5 \%$ with respect to the results obtained for calibration images. Suction was the only parameter that was varied; the temperature was held constant. This point is particularly important because no previous studies have imposed suction-controlled cycles on soil specimens while monitoring the evolution of cracks. The image processing tool described in this paper makes it possible to determine the evolution of both the radial strain and the crack area over time with changes in suction.

\subsection{Volumetric strains}

Alonso et al. (2005) studied the impact of suction cycles, from $4 \mathrm{MPa}$ to $120 \mathrm{MPa}$, on clayey silt at a water content of $10.5 \%$ (a degree of saturation of $37 \%$ ) on an uncracked specimen. Samples were subjected to various vertical net stresses (92 kPa, $196 \mathrm{kPa}$ and $396 \mathrm{kPa}$ ). 
Their results showed an accumulation of shrinkage strain with the number of cycles and a convergence of the vertical strain towards a reversible state. Nowamooz and Masrouri (2008) studied the evolution of vertical strain in a soil specimen subjected to wetting and drying suction cycles between 0 and $2 \mathrm{MPa}$. The tested samples showed cumulative swelling strains during the cycles, which finally converged towards an equilibrium stage. All of the tests exhibited completely reversible behaviour after 2 to 3 suction cycles.

In this study, the strains also converged to a reversible state after an influential first drying phase. Indeed, there was a $5 \%$ decrease between the vertical strains at the end of the first drying phase and at the end of the third drying phase, whereas the radial strains after the third cycle were $5 \%$ higher than the radial strains after the first cycle. It seems that the presence of cracks did not influence the relationship between the vertical strains and the suction cycle.

\section{2. $\mathrm{CIF}^{\star}$ and $\mathrm{CIF}_{\text {tot }}$}

Another unique aspect of this study was the use of an image processing method to determine the radial strains, which made it possible to distinguish between crack area and shrinkage area. In previous studies (Miller et al. 1998; Yesiller et al. 2000, Tang et al. 2008, 2009, 2011), the shrinkage area was eliminated to limit the CIF determination to the inner part of the specimen $\left(\mathrm{CIF}=\mathrm{CIF}^{*}\right)$. However, the evolution of the radial strains is also interesting because it may contribute to a better understanding of the cracking phenomenon.

As observed in section 4.I, the evolution of the $\mathrm{CIF}^{*}$ and the $\mathrm{CIF}_{\text {tot }}$ became reversible after the first cycle (Fig. 13). For each phase, the $\mathrm{CIF}^{\star}$ (and $\mathrm{CIF}_{\text {tot }}$ ) changed sharply when suction was first imposed; then, the evolution became more gradual, until it converged towards an equilibrium state. The value of $\mathrm{CIF}^{*}$ (and $\mathrm{CIF}_{\text {tot }}$ ) at the end of the wetting phase (drying phase) did not change with the number of cycles.

Tang et al. (2008) reported a decrease of the CIF* with an increasing number of wetting/drying cycles. Their study concerned the impact of very intense drying/wetting cycles 
on an initially saturated slurry. The cycles imposed included an oven drying phase (between $30^{\circ} \mathrm{C}$ and $50^{\circ} \mathrm{C}$ ), and a direct imbibition phase. In their study, the initial unconsolidated state and the high water content of the soil slurry could explain the high $\mathrm{CIF}^{*}$ value obtained during the first drying phase. During the subsequent cycles, soil densification, which could not be quantified during their tests, might have been responsible for the decrease in the CIF*. The

416 simultaneous measurement of each geometric parameter is needed to explain the sample 417 evolution.

418 On the contrary, Yesiller et al. (2000) and Tay et al. (2001) demonstrated an increasing CIF* 419 with an increasing number of wetting/drying cycles. However, it should be noted that they 420 tested large surface-compacted specimens $(800 \mathrm{~mm}$ to $1500 \mathrm{~mm}$ in width and $200 \mathrm{~mm}$ to $421500 \mathrm{~mm}$ in depth). The wetting phase was imposed by watering the soil surface, which may 422 have led to local moisture gradients. Desiccation was achieved by air drying coupled with 423 ventilation at the soil surface, which may have induced non-uniform drying. These results 424 suggest that intense and non-uniform wetting/drying cycles favour preferential crack initiation 425 and lead to the creation of dense crack patterns (a 5\% CIF* value was obtained by Yesiller et 426 al., 2000). Moreover, the crack pattern observed by Tay et al. (2001) was influenced by the 427 compaction procedure (a pneumatic hammer attached to a vibrating plate); they noted that 428 some of the cracks followed the surface depression caused by the compaction equipment.

429 In this study, the stabilisation of $\mathrm{CIF}^{*}$ values observed after the first cycle may be explained 430 on the one hand by the static compaction of the soil specimen, which avoided the formation 431 of weak zones and preferential crack initiation and propagation, and on the other hand by the 432 suction-controlled test process, which permitted gradual and uniform wetting/drying 433 conditions at the soil surface. However, more results are needed to confirm this observation.

\subsection{Hysteresis loops}


435 The evolution of the vertical strains, radial strains, $\mathrm{CIF}^{*}$ and $\mathrm{CIF}_{\text {tot }}$ with respect to the water content showed hysteresis loops. Indeed, for a given cycle, the wetting and drying curves were not identical for any of the parameters studied.

The hysteresis loops corresponding to the vertical and radial strains are narrow (Fig. 8, 12), whereas the $\mathrm{CIF}^{\star}$ loops are large (Fig. 15). Moreover, the comparison of the evolution of CIFtot and CIF* with the mass water content (Fig. 15) showed that the main part of the hysteresis loops were linked to the inner crack formation. The difference between these two curves mainly corresponded to the plastic volumetric deformation accumulated during the first drying phase.

The hysteresis loops were also observed in continuous media in previous studies that were focused on the evolution of volumetric strain with the number of suction cycles (Alonso et al., 2005; Nowamooz and Masrouri, 2008). After Gens and Alonso (1992), in an expansive soil, theses loops for volumetric strains are in large part due to the two structural levels in the fabric: micro and macro-structure. During the first drying phase, with the loss of water content and the increase of suction, a rearrangement of the macro-structure appears which induces a densification of the specimen with decreasing the volume of the large pores and inducing a decrease of the mean height and the diameter of the specimen. These strains are in a large part irreversible due to the hysteresis effect which could be attributed to: geometric nonuniformity of individual pores, resulting from the "Ink Bottle" effect; different spatial conductivity during drying and wetting process, variation in liquid-solid contact angle; and air entrapment (Hillel, 1980; O'Kane, Pokrovskii, \& Flynn, 2004). For instance, the hysteresis loops in cracked specimen could be explained in the same manner as in continuous samples. Further investigations are needed to confirm this hypothesis..

\section{CONCLUSIONS}

In this paper, a device for studying the evolution of soil specimens subjected to controlled wetting/drying cycles was presented. The device, coupled with an image processing method, 
allows the simultaneous measurement of the evolution of various soil parameters, such as

462

463

464

465

466

467

468 the water content, the vertical strains, the radial strains, and the crack area evolution over time. This device and the associated image processing software make it possible to study the evolution of these parameters during wetting and drying cycles applied by varying the suction, rather than just the evolution of the equilibrium value of the parameters at the end of each wetting and drying phase. 3 suction cycles were applied to a circular test specimen composed of a mixture of bentonite and silt in this study. The following observations were made:

- $\quad$ All parameters exhibited hysteresis loops.

- The first cycle was the most influential.

- All of the studied parameters converged towards a reversible state as the number of suction cycles increased.

During the various tests involved in the development of the procedure, circular specimens of different sizes were successfully tested, and the image processing was able to determine the evolution of cracks over time. This procedure can be used in a laboratory environment without it being necessary to take into account the laboratory lighting system. As a consequence, the impact of varying suction intensity on a cracked soil surface, as well as the impact of the initial state of the specimen (water content after compaction, clay content and dry density) can also be studied. This can lead to a better understanding of the relation between suction and cracking in soft soils.

\section{Acknowledgements}

The authors thank M. R. Caël for his technical assistance with electronics and test conception, and M. C. Morlot and M. E. Lefevre for their technical assistance with photography issues. 


\section{References}

487

488

489

490

491

492

493

494

495

496

497

498

499

500

501

502

503

504

505

506

507

508

509

510

511

512

513

514

515

516

517

518

519

520

521

522

Abdelmalak, R. 2007. Soil structure interaction for shrink-swell soils. A new design procedure for foundation slabs on shrink-swell soils. Ph.D. Thesis, Texas A\&M. University.

Albrecht, B., Benson, C., Members, 2001. Effect of Desiccation on Compacted Natural Clays. Journal of Geotechnical \& Geoenvironmental Engineering 127 (1), 67-75.

Alonso, E.E., Romero, E., Hoffemann, C, Garía-Escudero,E., 2005. Expansive bentonite/sand mixtures in cyclic controlled suction drying and wetting. Engeneering Geology 81, 213-226.

ASTM, 1998. Standard test Method for Liquid Limit, Plastic Limit, and Plasticity Index of Soils. In annual Book of ASTM standards vol. 04.08, 519-529, American Society for Testing Materials, Designation D4318-98.

ASTM, 2006. Standard test Method for Specific Gravity of Soil Solids by Gas Pycnometer. In annual Book of ASTM standards vol. 15.02. American Society for Testing Materials, Designation D5550-06.

ASTM, 2009. Standard Test Method for Methylene Blue Index of Clay. In annual Book of ASTM standards vol. 15.02. American Society for Testing Materials, Designation C837-09.

Atique, A., Sanchez, M., 2011. Analysis of cracking behavior of drying soil. $2^{\text {nd }}$ International Conference on Environmental Science and Technology IPCBEE 6, IACSIT Press Singapore vol 1, 66-70

Blatz, J.A., Cui,Y-J., Oldecop, L., 2008. Vapour equilibrium and osmotic technique for suction control . Geotechnique Geotechnical Engineering 26, 661-673.

Boivin, P., Garnier, P., Tessier, D., 2004. Relationship between clay content, clay type, and shrinkage properties of soil samples. Soil Science Society of America Journal 68, 1145-1153.

Bronswijk, J., 1991. Relation between vertical soil movements and water-content changes in cracking clays, Soil Science Society of America Journal 55, 1220-1226.

Doyle, W., 1962. Operation useful for similarity-invariant pattern recognition. Journal of the Association for Computing Machinery 9, 259-267.

Drumm, E. C., Boles, D.R., Wilson, G., V., 1997. Desiccation cracks result in preferential flow. Environmental Geotechnics 15(2), 22-25

Eigendbrod, K.D., 2003. Self-healing in fractured fine-grained soils. Canadian Geotechnical Journal 40, 435-449.

Elias, E., Salih, A., Alaily, F., 2001. Cracking patterns in the Vertisols of the Sudens Gezira at the end of dry season. International Agrophycs 15(3), 151-155.

Gens, A., Alonso, E.E., 1992. A framework for the behaviour of unsaturated expansive clays. Canadian Geotechnical Journal 29, 1013-1032.

Glasbey, C.A., 1993. An analysis of histogram-based thresholding algorithms. CVGIP:

Graphical Models and Image Processing 55, 532-537. 
Hallaire, V., 1991. Une méthode d"analyse bidimentionnelle du retrait d'échantillons naturels de sol. Science Du Sol 29(2), 147-158.

Hewitt, P.J., Philip, L.K., 1999. Problems of clay desiccation in composite lining systems. Engineering Geology 53, 107-113.

Hillel, D. (1980). Fundamentals of soil physics (p. 413). New York, NY: Academic Press.

Hillel, D., 1988. L'eau et les sols, principes et processus physiques Louvain-la-Neuve: Academia. ISBN: 2-87209-015-0. Collection PEDASP.287p

Huang, L-K., Wang, M.J J., 1995. Image thresholding by minimizing the measure of fuzziness. Pattern Recognition 28(1), 41-51

ISO, 1999. ISO 483 : Petites enceintes de conditionnement et d'essai utilisant des solutions aqueuses pour maintenir l'humidité relative à une valeur constante. International Organisation for Standardization, 11p

Jahangir, E., Deck, O., Masrouri, F., 2011. Influence of foundation embedding on clays shrinkage-swellling hazard consequences. $3^{\text {rd }}$ International Symposium on Geotechnical Safety and Risk, Munich, Germany 2011, 117-124.

Jahangir, E., Deck, O., Masrouri, F., 2012. Estimation of the ground settlement beneath foundations due to shrinkage of clayey soils. Canadian Geotechnical Journal 49(7), 835-852

Kapur, J., Sahoo, P., Wong, A., 1985. A new method for graylevel picture thresholding usig the entropy of the histogram. Computer Graphics and Image Processing 29(3), 273-285.

Kittler, J., Illingworth, J., 1986. Minimum error thresholding. Pattern Recognition 19, 41-47

Konrad, J.-M., Ayad, R., 1997. An Idealized Framework for the Analysis of Cohesive Soils Undergoing Desiccation. Canadian Geotechnical Journal 34, 477-488.

Kleppe, J.H., Olson, R.E., 1985. Desiccation cracking of soil barrier. Hydraulic Barrier in Soil and Rock, ASTM STP 874, A.I.Johnson, R.K. Frobel, N.J. Cavali, and C.B. Petterson, Eds., American Society for Testing and Materials, Philadelphia, 1985, 263-275.

Lakshmikantha, M, Prat, P., Ledesma, A., 2009. Image Analysis for the quantification of a developing crack network on a drying soil. Geotechnical Testing Journal 32 (6), 505-515.

Li, C.H., Lee, C.K., 1993. Minimum Cross Entropy Thresholding. Pattern Recognition 26(4), 617-625.

Li, C.H., Tam, P.K.S.,1998. An Iterative Algorithm for Minimum Cross Entropy Thresholding. Pattern Recognition Letters 18(8), 771-776.

Lide, D.R., 2002. Handbook of chemistry and physics. $82^{\text {nd }}$ edition, CRC press, 15.25-15.26.

Lloret, A., Ledesma, A., Rodriguez, R., Sanchez, M., Olivella, S., Suriol, J, 1998. Crack initiation in drying soils. Proceedings of the Second International Conference on Unsaturated Soils, Bejing China, International Academic Publisher, 497-502. 
Maisa M.J., Kleeman P.W., Melchers R.E. (2004). Soil/structure interaction modelling of masonry for reliability studies. Journal of structural Engineering 130, 641-649.

Malawitz, K., 1998. Crack-healing in damaged compacted clay liners in waste deposits. In Proceedings of the $3^{\text {rd }}$ International Congress on Environmental Geotechnics, Lisbon, Portugal, 7-11 September, 347-352.

Miller, C.J., Mi, H., Yesiller, N., 1998. Experimental Analysi of Desiccation Crack Propagation in Clay Liners. Journal of the American Water Ressources Association 34 (3), 677-686.

Nelson, J.D., Miller, D.J., 1992. Expansive soils: problems and practice in foundation and pavement engineering. John Wiley \& Sons Ltd., New York. 259 pages.

Nowamooz, H., Masrouri, F., 2008. Hydromechanical behavior of an expansive bentonite/silt mixture in cyclic suction-controlled drying and wetting tests. Enginnering Geology 101 (3-4) 154-164.

Nowamooz, H., Masrouri, F., 2010. Influence of suction cycles on the soil fabric of compacted swelling soil. Comptes Rendus Geosciences 342 (1), 901-910.

O'Kane, J. P., Pokrovskii, A., \& Flynn, D. (2004). The fest model for testing the importance of hysteresis in hydrology. Proceedings of EGU conference, vol. 6, 07303.

Omidi, G.H., Thomas, J.C., Brown, K.W., 1996. Effect of desiccation cracking on the hydraulic conductivity of a compacted clay liner, Water Air and Soil Pollution 89 (1-2), 91 103.

Otsu, N., 1979. A threshold selection method from gray-level histograms, IEEE Trans System, Man and Cybernetics Society 9(1), 62-66.

Peng, X., Horn, R., Peth, S., Smucker, A., 2006. Quantification of soil shrinkage in 2D by digital image processing of soil surface. Soil \& Tillage Research 91, 173-180.

Peron, H., Hueckel, T., Laloui, L., Hu, L., 2009. Fundamentals of desiccation cracking of finegrained oils : experimental charaterisation and mechanisms identification 46, 1177-1201.

Phifer, M., Boles, D., Drumm, E., Wilson, G.V., 1995. Comparative response of two barrier soils to post compaction water content variations. ASCE GSP 46, 591-608.

Prewitt, J.M.S., Mendelsohn, M.L.,1966. The analysis of cell images. Annals of the New York Academy of Sciences 128, 1035-1053.

Rasband, W.S., 2006. "ImageJ", National Institute of health, http://rsb.info.nih.gov/ij/

Rayhani, M.H.T., Yanful, E.K., Fakher, A., 2007. Desiccation-induced cracking and its effect on the hydraulic conductivity of clayey soils from Iran. Revue Canadienne de Géotechnique 44, 276-283.

Richards, B.G., 1974.Behaviour of unsaturated soils. Soils Mechanics-new horizons, American Elsevier, New York, 112-157. 
Ridler, TW., Calvard, S., 1978. Picture thresholding using an iterative selection method, IEEE Transactions on Systems. Man and Cybernetics 8, 630-632

Rodriguez, R., Sánchez, M., Ledesma, A., Lloret, A., 2007. Experimental and numerical analysis of desiccation of a mining waste. Canadian Geotechnical Journal 44(6), 644-658.

Sadek, S., Ghanimeh, S., El-Fadel, M., 2007. Predicted performance of clay-barrier landfill covers in arid and semi-arid environments. Waste Management 27, 572-583.

Serra, J., 1982. Image Analysis and Mathematical Morphology, Academic Press, London.

Shanbhag, A.G.,1994. Utilization of information measure as a means of image thresholding, Graph. Models Image Process. (Academic Press, Inc.) 56 (5), 414-419.

Sternberg, S., 1983. Biomedical Image Processing. Computer 16 (1), 22-34.

Tang, C., Shi, B., Liu, C., Zhao, L., Wang, B., 2008. Influencing factors of geometrical structure of surface shrinkage cracks in clayey soils. Engineering Geology 101, 204-217.

Tang, C.S., Cui, Y.J., Tang, A.M., Shi, B., 2010. Experimental Evidence on the Temperature Dependence of Desiccation cracking behavior of Clayey soil. Engineering Geology, 114, 261-266.

Tang, C.S., Cui, Y.J., Shi, B., Tang, A.M., Liu, C., 2011. Desiccation and cracking behaviour of clay layer from slurry state under wetting-drying cycles. Geoderma 166(1), 111-118.

Tariq, A., Durnford, D., 2001. Shrinkage and desiccation cracking in bentonite-sand landfill liners. Engineering Geology 60, 263-274.

Tay, Y., Stewart, D., Cousens, T., 2001. Shrinkage and desiccation cracking in bentonitesand landfill liners. Engineering Geology 60, 263-274.

Tsai, W., 1985.Moment-preserving thresholding: a new approach., Computer Vision, Graphics, and Image Processing 29, 377-393.

Velde, B., 1999. Structure of Surface Cracks in Soil Muds. Geoderma 93, 101-124.

Velde, B., 2001. Surface Cracking and Aggregate Formation Observed in a Renzina Soil. Geoderma 99, 203-211.

Vogel, H., Hoffmann, H., Roth, K., 2005. Studies of Crack Dynamics in Clay Soil I: Experimental Methods, Results and Morphological Quantification. Geoderma 125, 203-211.

Yen, JC, Chang S., 1995. A New Criterion for Automatic Multilevel Thresholding. IEEE Trans. On Image Processing 4(3), 370-378.

Yesiller, N., Miller, C., INCI, G., Yaldo, K., 2000. Desiccation and cracking behavior of three compacted landfill liners soils. Engineering Geological 57, 105-121.

Yuen, K., Graham, J., Janzen, P., 1998. Weathering induced fissuring and hydraulic conductivity in natural plastic clay. Canadian Geotechnical Journal 35 (6), 1101-1108. 
628 Zack, G.W., Rogers, W.E., Latt, S.A., 1977. Automatic measurement of sister chromatid 629 exchange frequency. Journal of Histochemistry \& Cytochemistry 25 (7), 741-753.

630 


\begin{tabular}{|c|c|c|c|c|}
\hline & Norme & $\begin{array}{l}\text { Xeuilley } \\
\text { silt }\end{array}$ & Bentonite & 40/60Mixture \\
\hline Liquid limit (\%) & ASTM,1993 & 36.8 & 117 & 82.2 \\
\hline Plastic limit (\%) & $\begin{array}{l}\text { ASTM, } \\
1993\end{array}$ & 27.6 & 41.2 & 29.6 \\
\hline Plasticity Index (\%) & $\begin{array}{l}\text { ASTM, } \\
1993\end{array}$ & 9.2 & 75.8 & 52.6 \\
\hline $\begin{array}{l}\text { MVB (mg/g) (Sahin et al., } \\
\text { 2013) }\end{array}$ & $\begin{array}{l}\text { ASTM, } \\
2009\end{array}$ & 31.3 & 184.1 & 115.3 \\
\hline Specific density $(\mathrm{g} / \mathrm{cm} 3)$ & $\begin{array}{c}\text { ASTM, } \\
2006\end{array}$ & 2.65 & 2.55 & 2.58 \\
\hline
\end{tabular}

632

633 Table 2. Threshold algorithm ImageJ functions

\begin{tabular}{ll}
\hline $\begin{array}{l}\text { Algorithm threshold } \\
\text { ImageJ function }\end{array}$ & References \\
\hline Huang & Huang and Wrang, (1995) \\
Intermodes & Prewitt and Mendelsohn, (1966) \\
IsoData & Ridler and Calvard, (1978) \\
Li & Li and Lee, (1993, 1998) \\
MaxEntropy & Kapur et al., (1985) \\
Mean & Glasbey (1993) \\
MinError & Kittler and Illingworth, (1996) \\
Minimum & Prewitt and Mendelsohn, (1966) \\
Moments & Tsai (1985) \\
Otsu & Otsu (1979) \\
Percentile & Doyle (1962) \\
RenyiEntropy & Kapur et al., (1985) \\
Shanbhag & Shanbhag (1994) \\
Triangle & Zack et al., (1977) \\
Yen & Yen et al., (1995) \\
\hline
\end{tabular}

634 
636 Table 3. Shrinkage area (S) and its relative error for selected functions (calibration image $\left.637 \quad \mathrm{n}^{\circ} 1\right)$

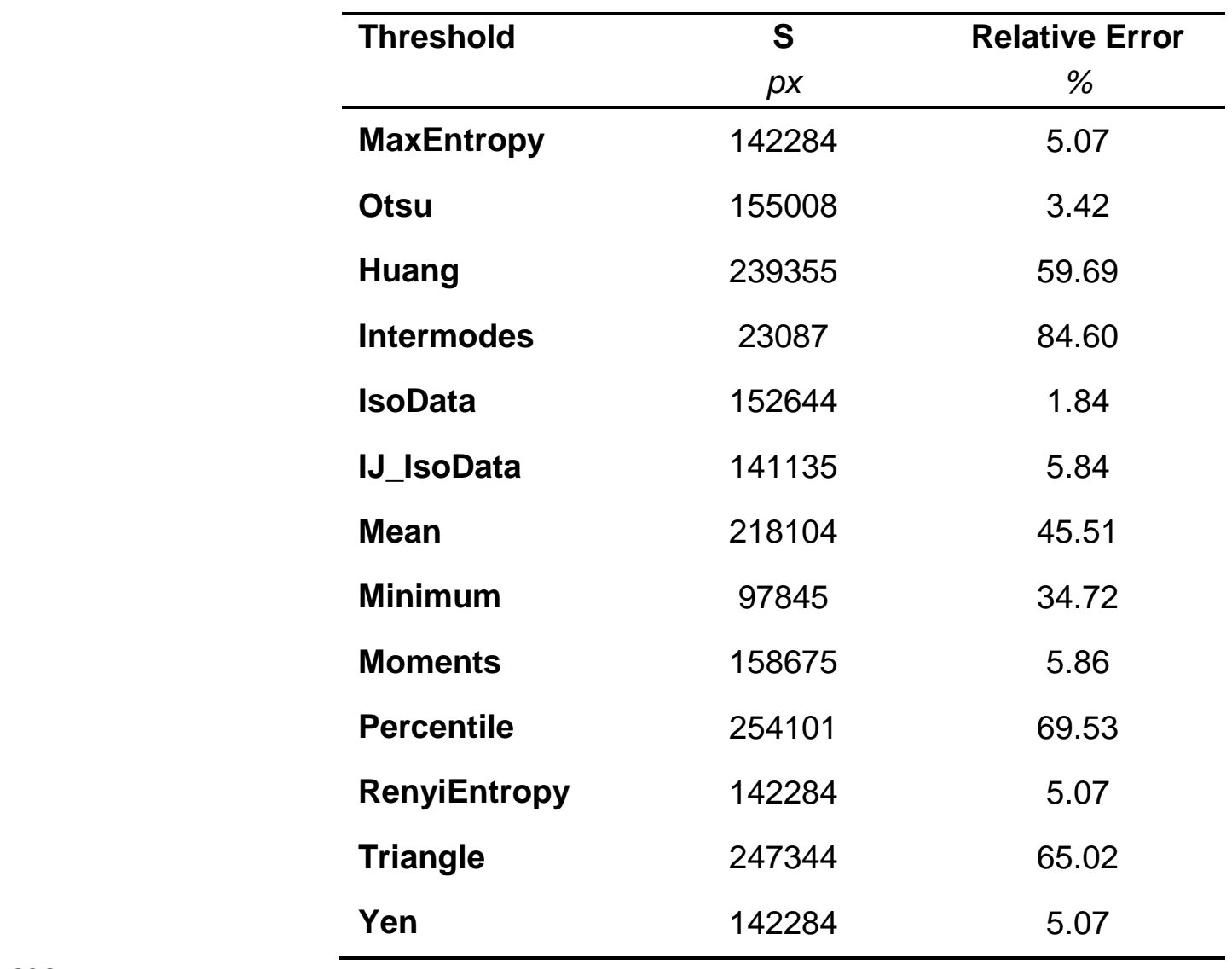


639 Table 4. Result of relative error of shrinkage area according to the used threshold algorithm 640 for the image of calibration $n^{\circ} 2$

\begin{tabular}{lcc}
\hline Threshold & S & Relative Error \\
& $p x$ & 2.60 \\
\hline MaxEntropy & 49166 & 52.71 \\
Otsu & 77086 & 37.47 \\
IsoData & 69387 & 16.87 \\
IJ_IsoData & 58989 & 32.38 \\
Moments & 66819 & 4.54 \\
RenyiEntropy & 48185 & 2.60 \\
Yen & 49166 & \\
\hline
\end{tabular}

641
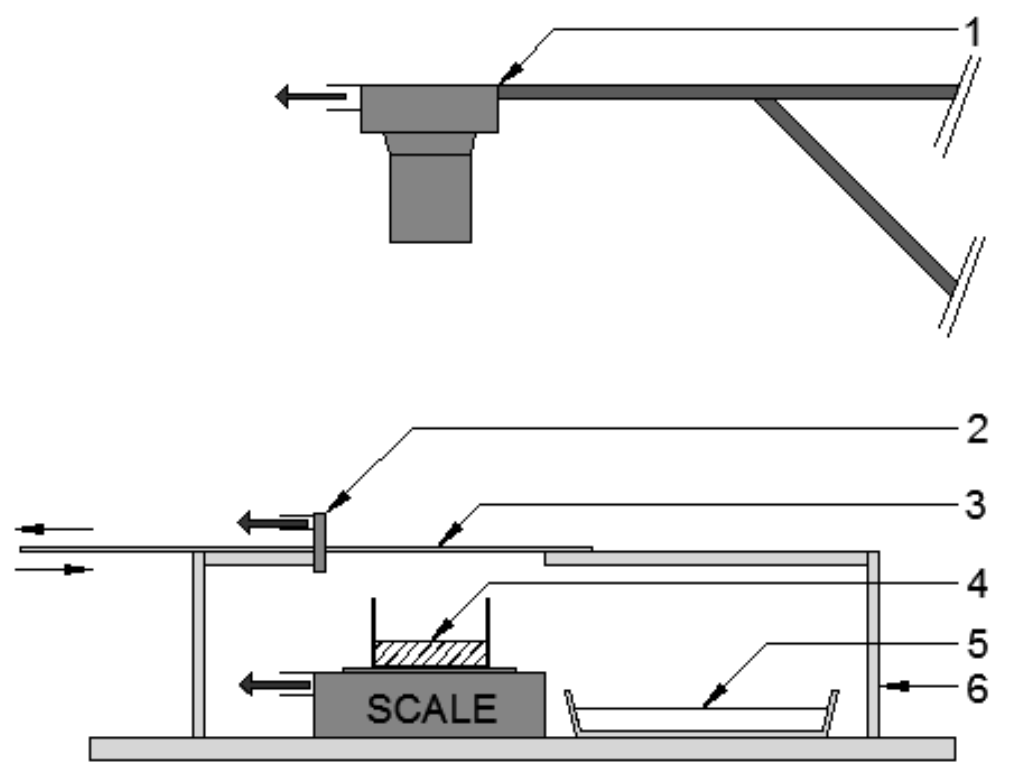

$\longleftarrow$ to the monitoring system

1: camera 2: laser distance sensor 3 : sliding glass pane

4: specimen 5: salt solution

6: glass hermetic container

642

643 Fig.1. Schema of the experimental device 


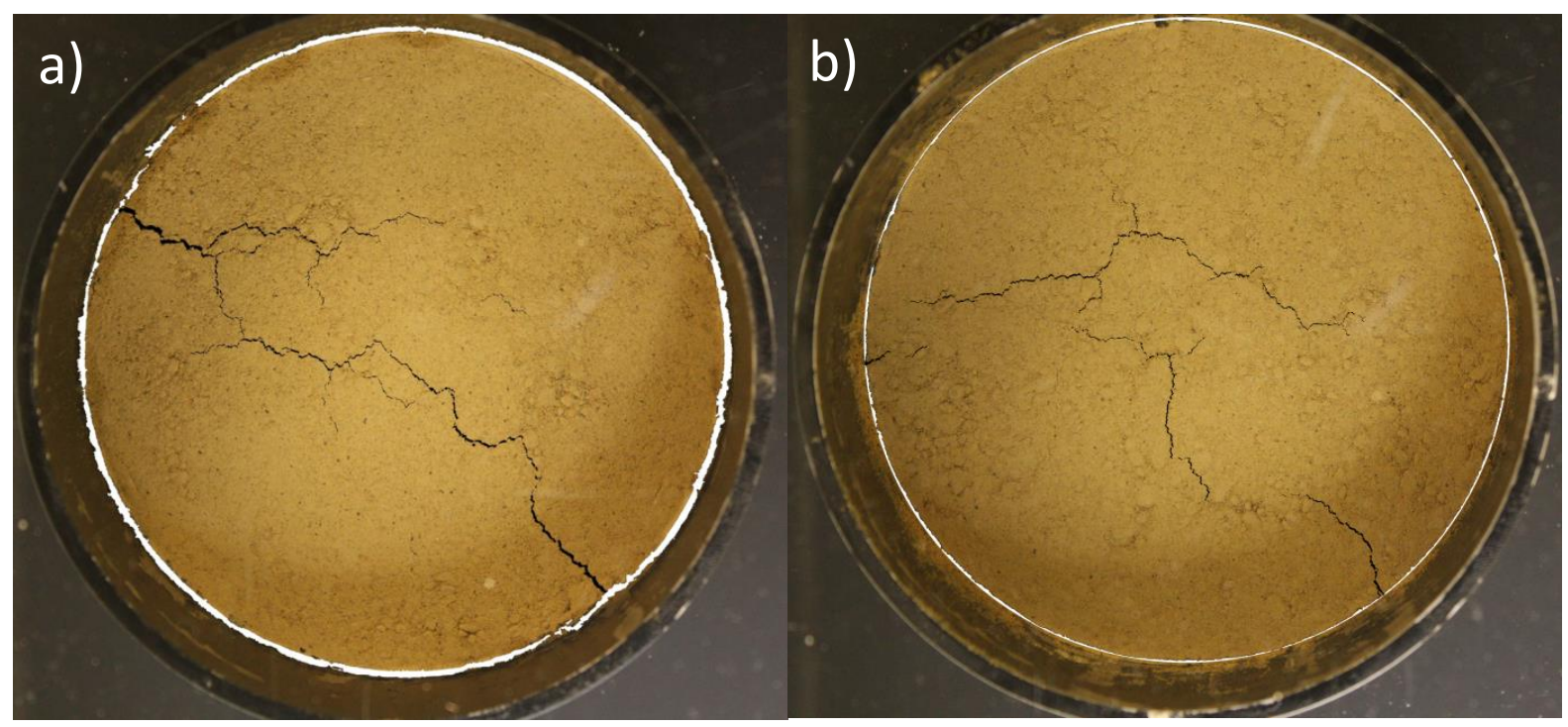

645 Fig. 2: Image of calibration $n^{\circ} 1$ after manual determination of the shrinkage area and the 646 crack area (a) and image of calibration $n^{\circ} 2$ after manual determination of the shrinkage area 647 and the crack area (b)

a) Raw image

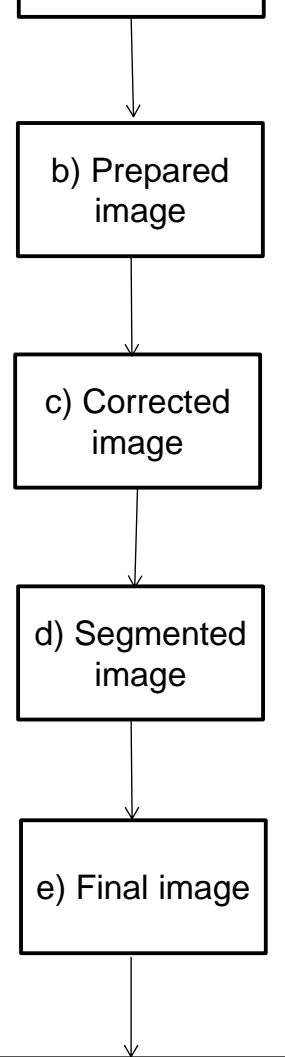

Shrinkage area determination Shrinkage maximal intensity

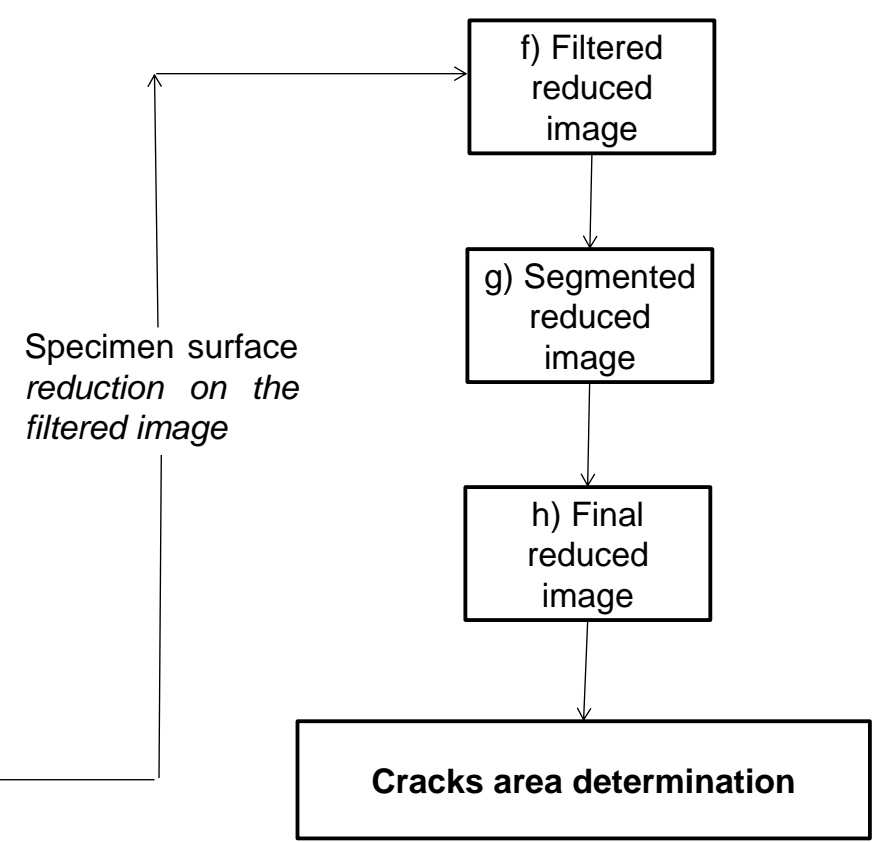

Fig.3. Chart of the image processing method 

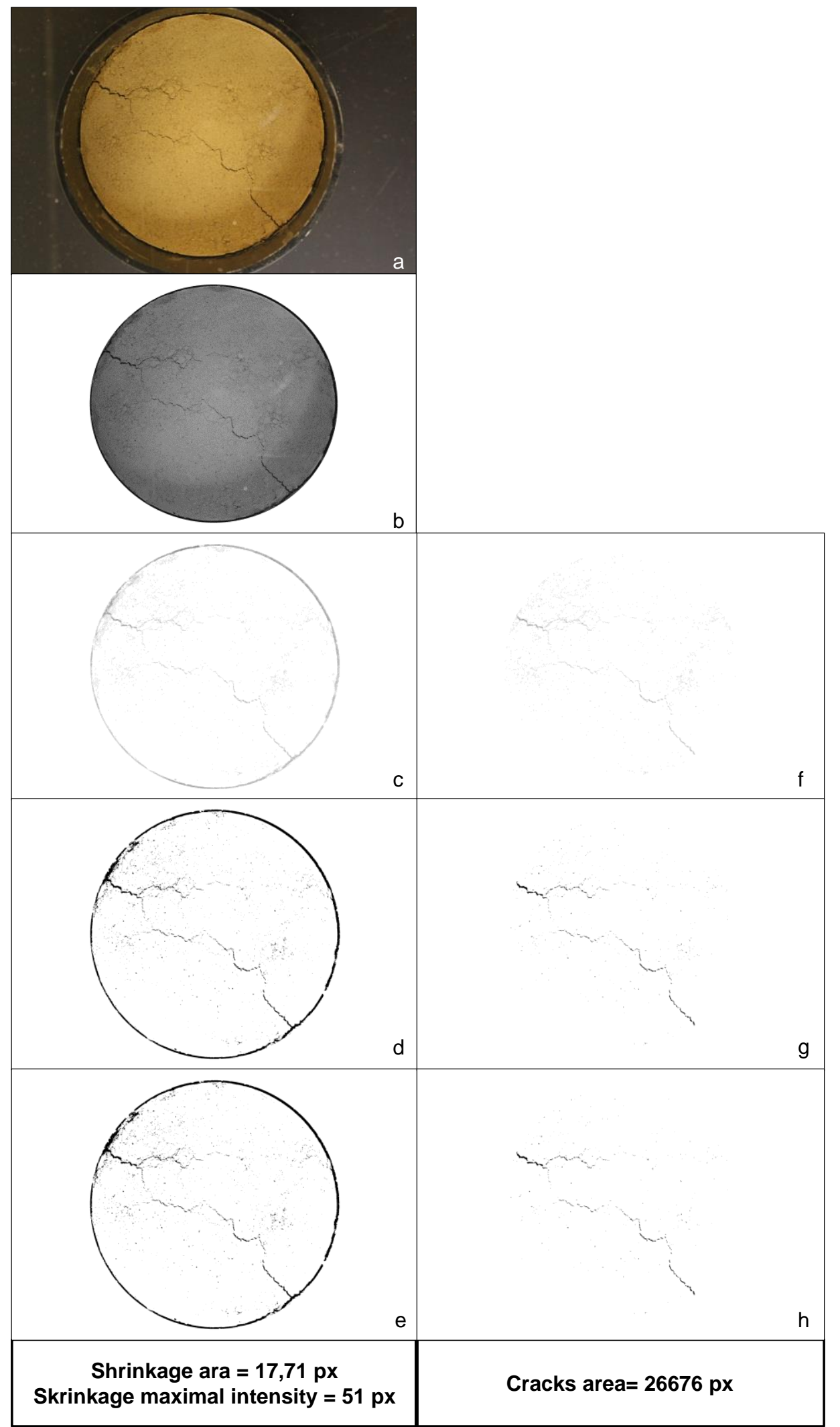

653 Fig.4. The different stages of the image processing method applied to the calibration image $654 \mathrm{n}^{\circ}$ 1: a) raw image b) prepared image, c) corrected image d) segmented image e) final image 655 f) reduced corrected image $g$ ) segmented reduced image $h$ ) final reduced image 


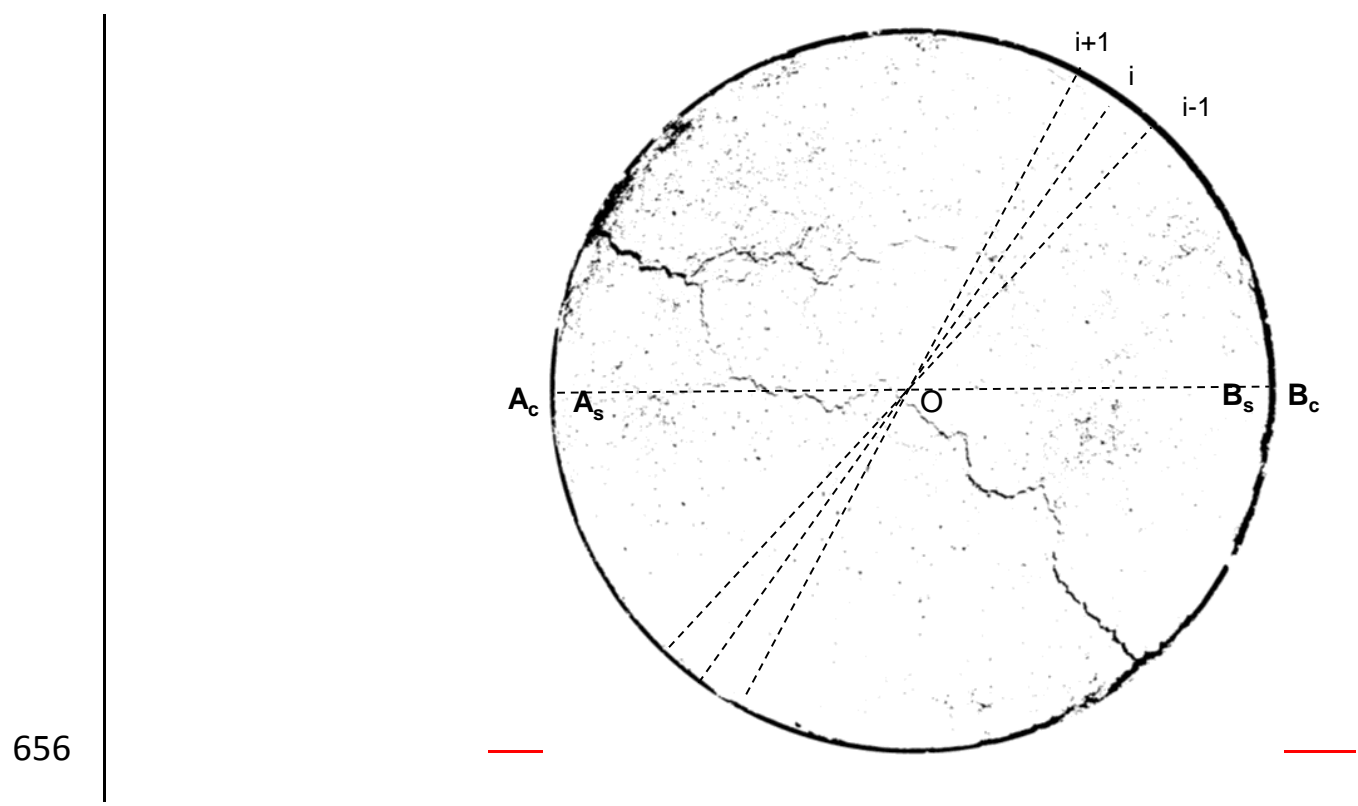

657 Fig.5. Diameter algorithm illustration for the given diameter of the final image of calibration 658

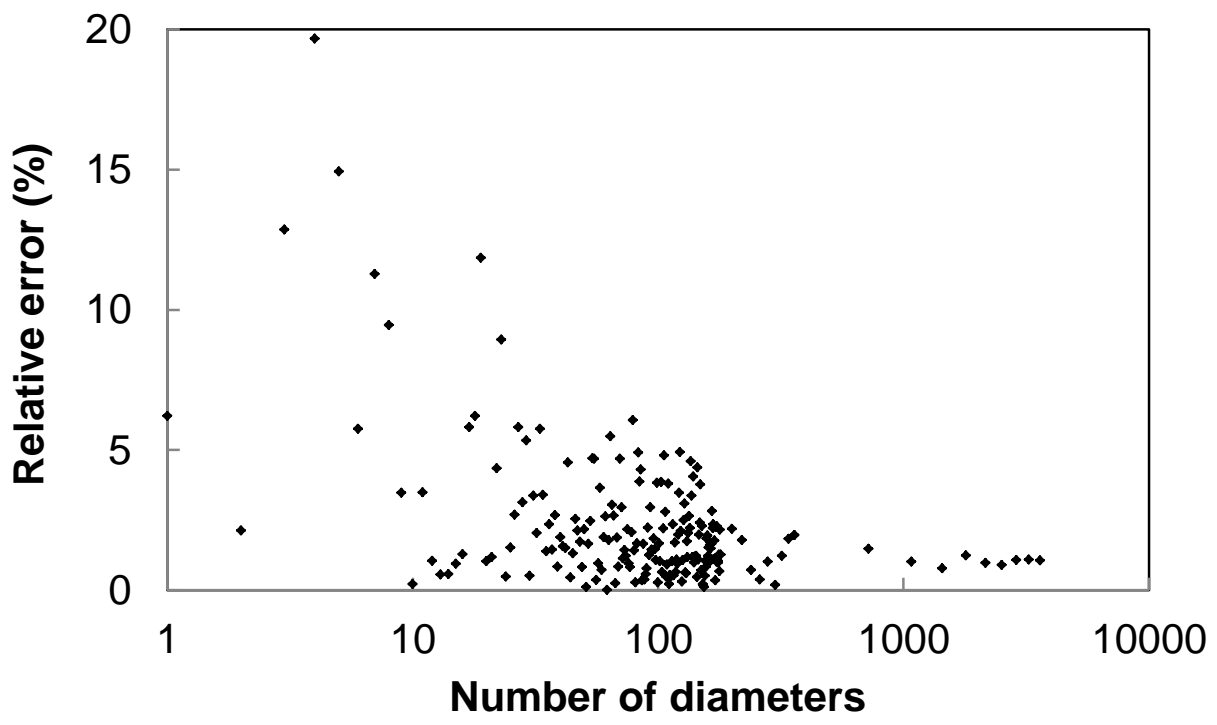

659

Fig.6. Impact of the number of diameters considered in the diameter algorithm on the relative 661 error of the shrinkage area prediction for the image of calibration 
a)

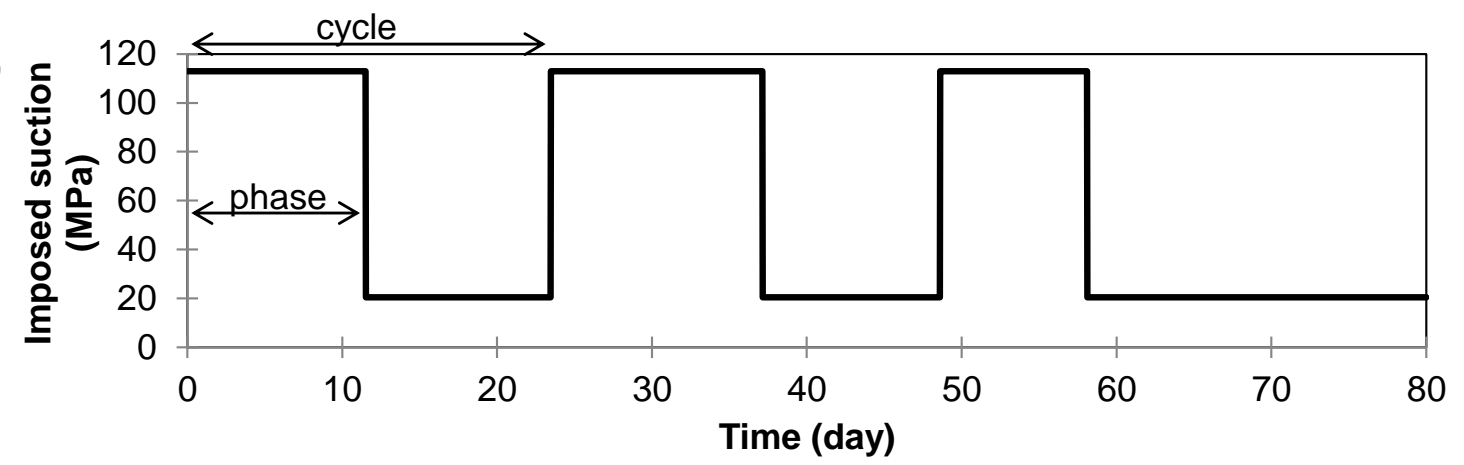

b)

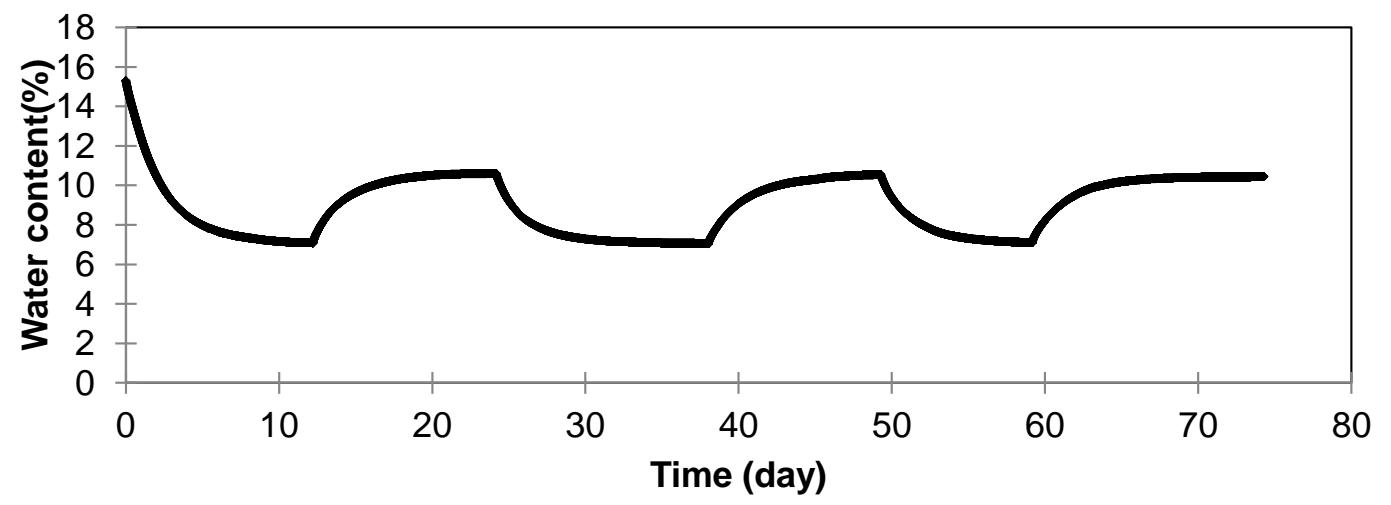

c)

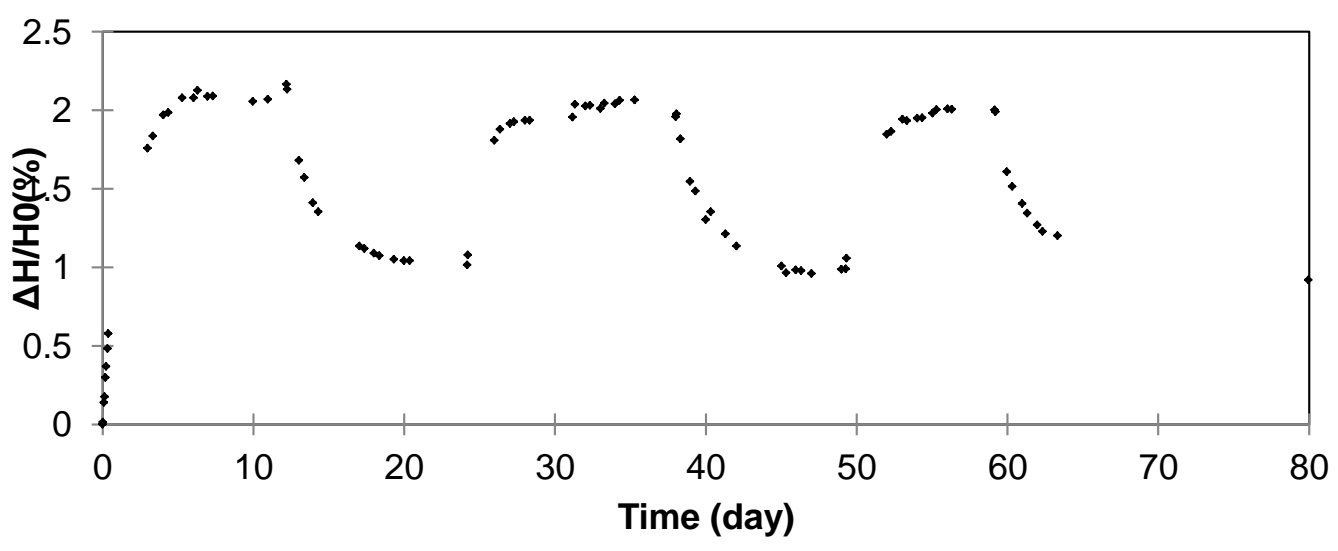

Fig.7. Evolution of the measured parameters over time during the test: a) The imposed 665 suction, b) The specimen water content, c) The vertical shrinkage 


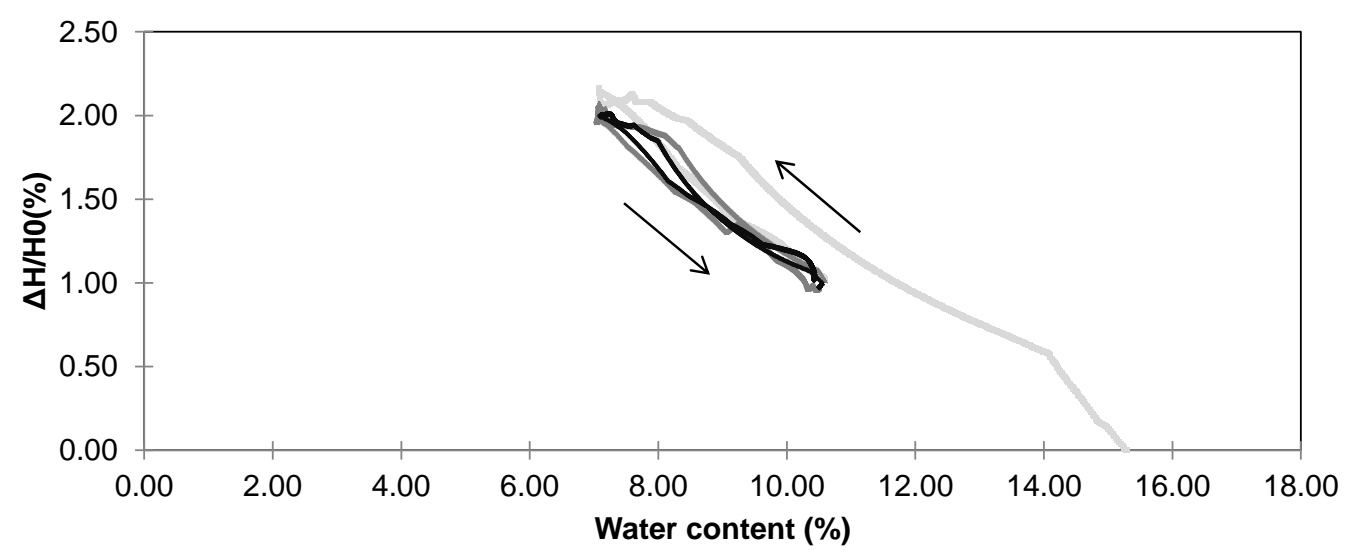

668

1st cycle 2nd cycle $\cdot 3$ rd cycle

669

Fig.8. Evolution of the vertical strains with water content

670

a)

e)

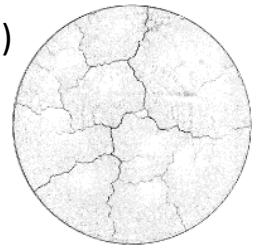

b

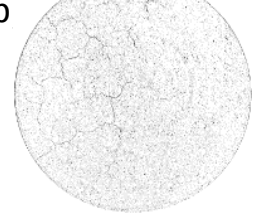

c)

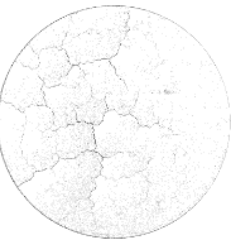

f)

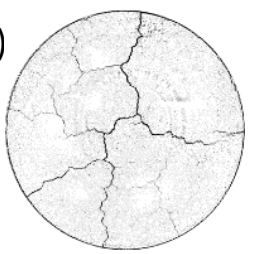

g) d)
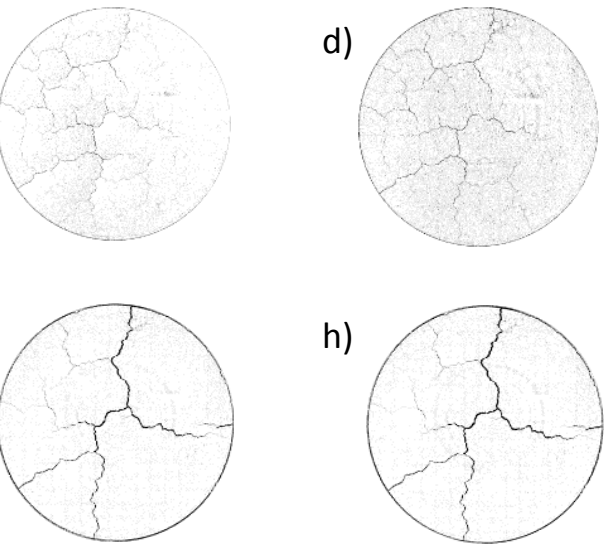

h)

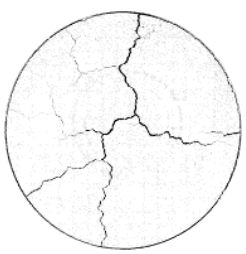

672 Fig.9. Evolution of the crack surface during the first phase of drying. a) Initial state*, b) after 4

$673 h^{*}$, c) after $6 h^{*}, d$ ) after $10 h^{*}$, e) after $\left.20 h^{*}, f\right)$ after $\left.44 h^{*}, g\right)$ after 5 days $\left.{ }^{*}, h\right)$ after 11.5 674 days*

675

*: the contrast of these images was increased to improve the specimen cracks observation in this figure.

676 

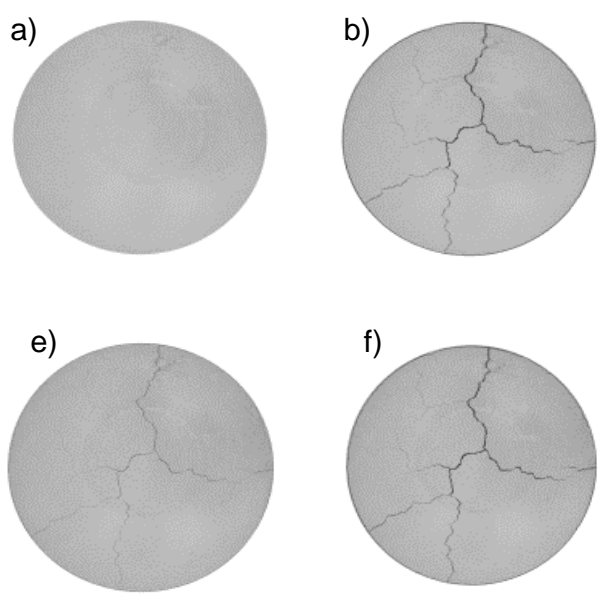

c)
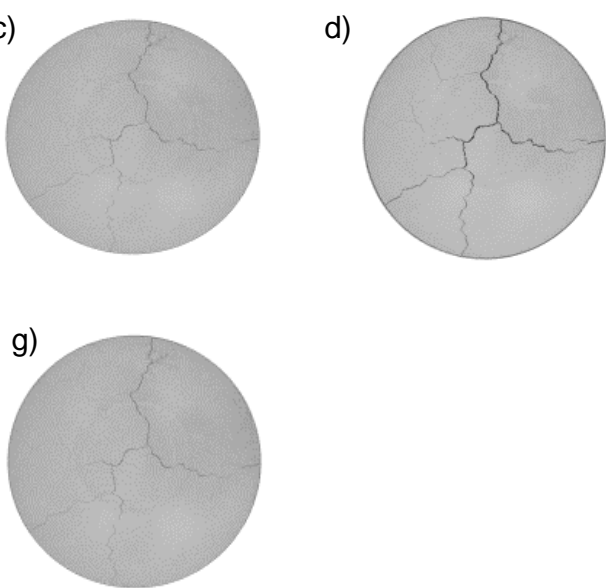

677

Fig.11. Evolution of horizontal strains over time

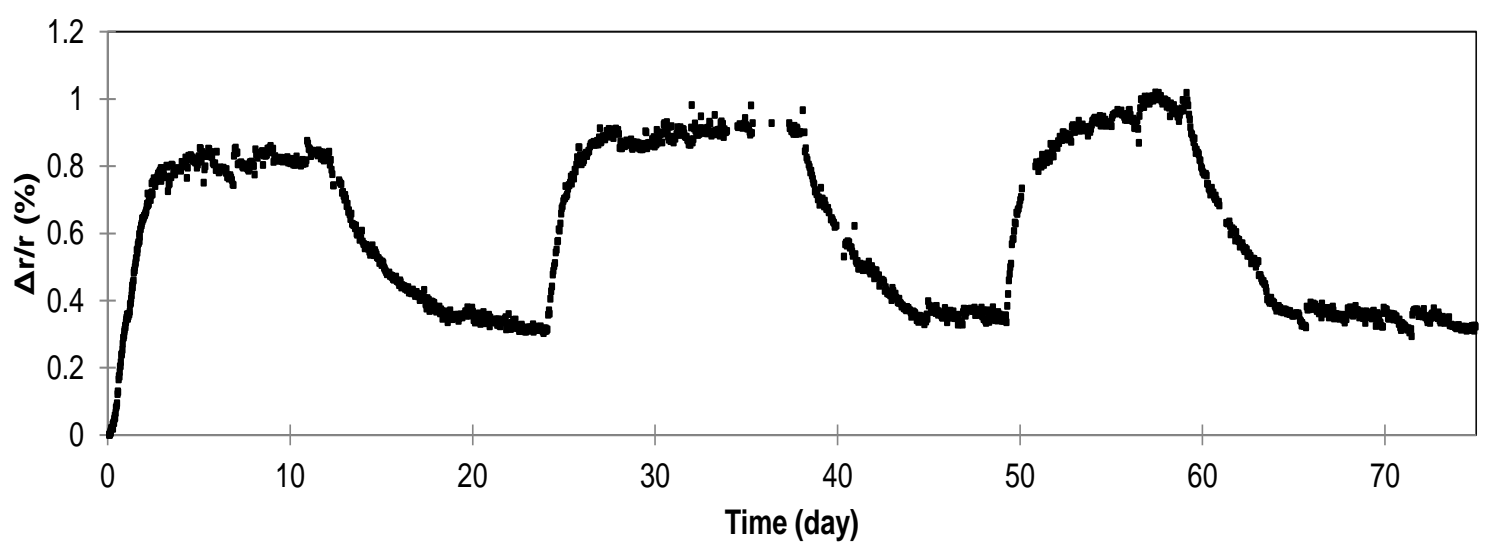




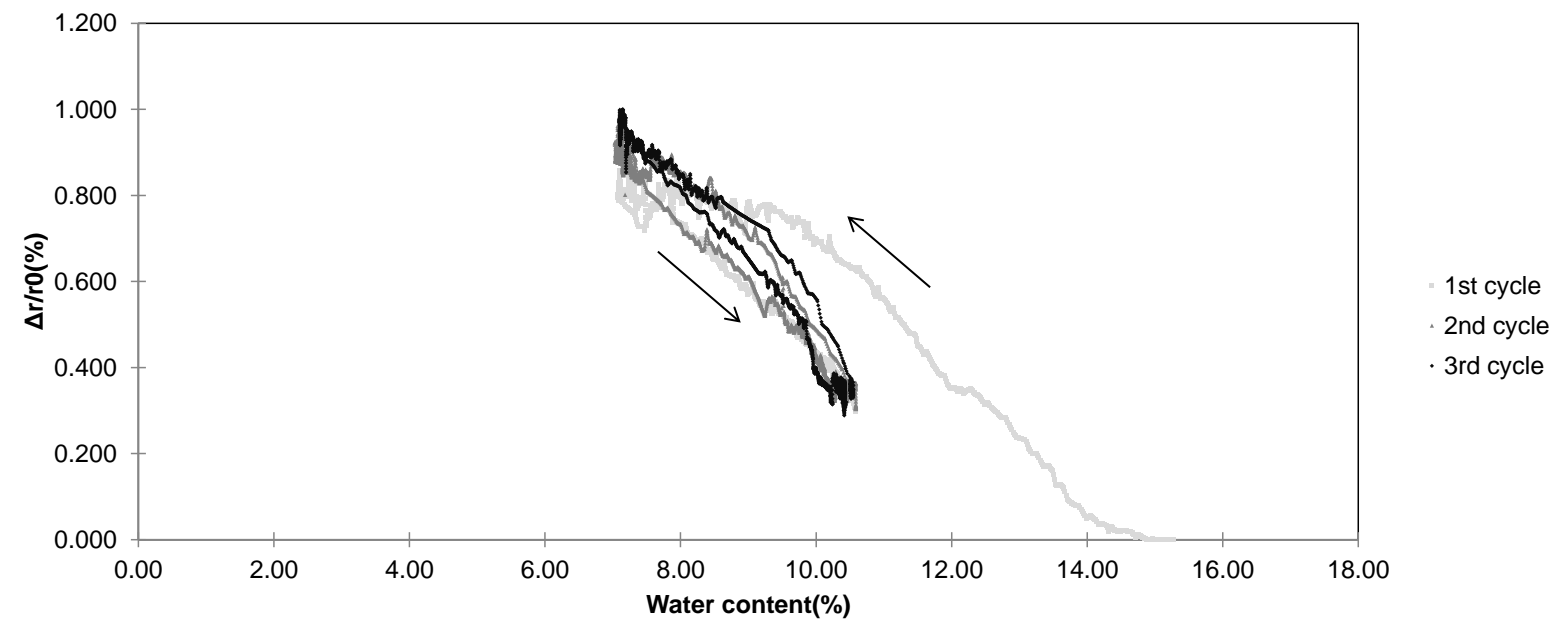

687

688 Fig.12. Evolution of radial strain with water content

689

690

691

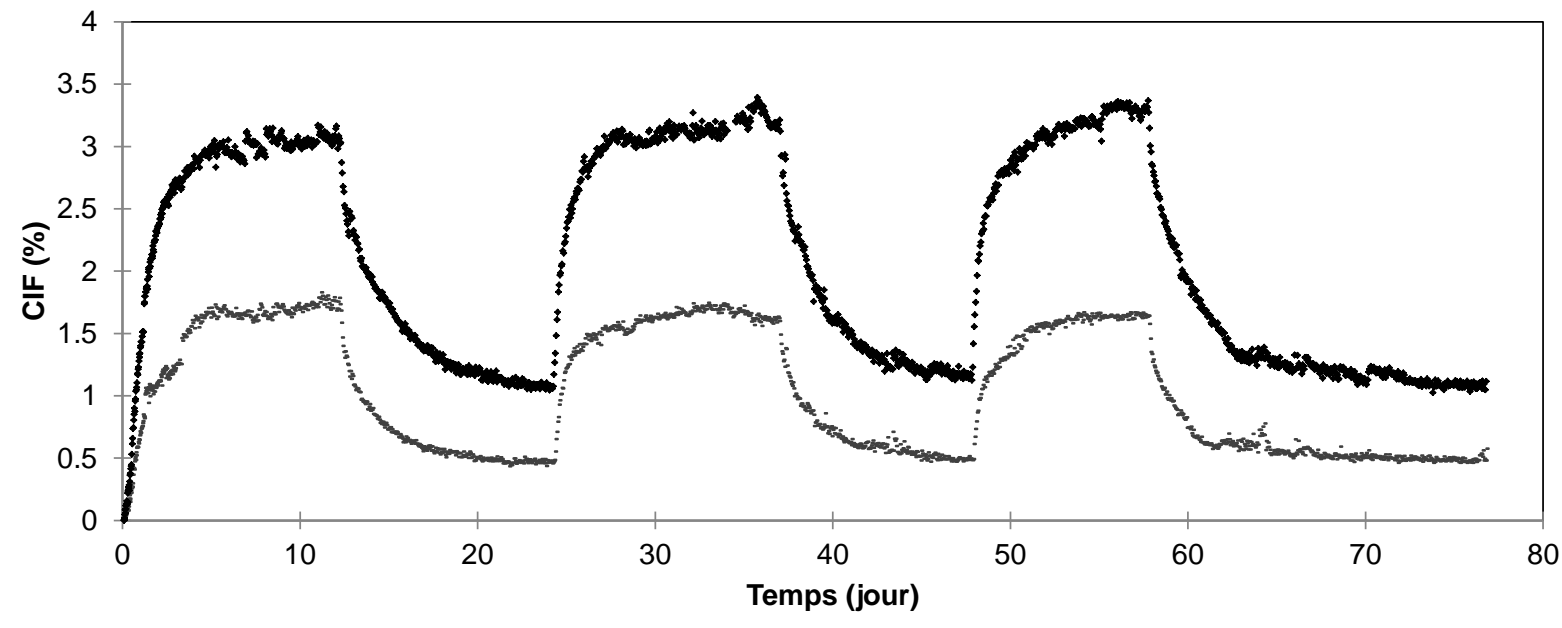

692

$$
\cdot \mathrm{CIF}^{*} \cdot \mathrm{CIF} \text { tot }
$$

693 Fig.13. Evolution of the $\mathrm{CIF}^{*}$ and $\mathrm{CIF}_{\text {tot }}$ over time

694

695 

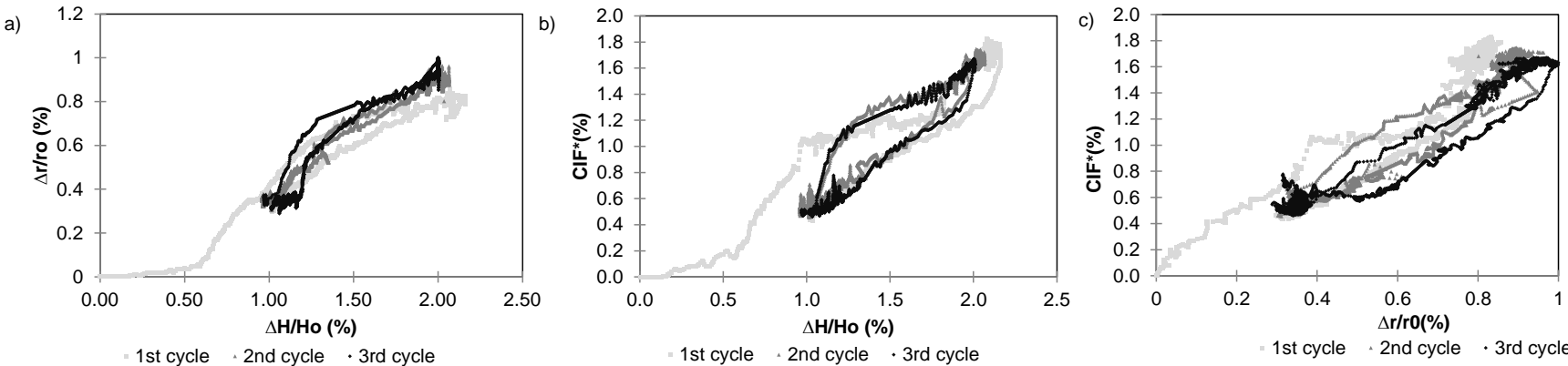

696

Figure 14: Evolution of measured parameters a) The radial strains with the vertical strains b)

$698 \mathrm{ClF}^{*}$ with vertical strains c) $\mathrm{CIF}^{*}$ with radial stains

699 

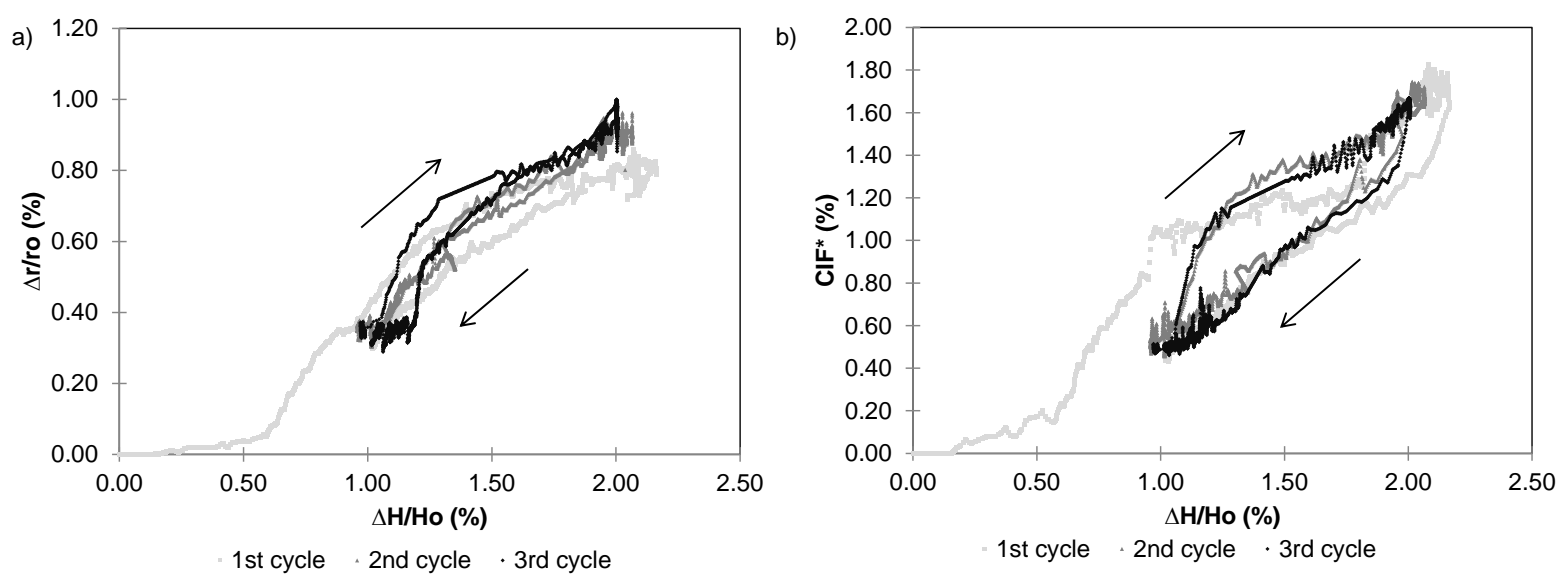

Fig.14. Evolution of the measured parameters with $\Delta \mathrm{H} / \mathrm{Ho}$, a) radial strains, b) $\mathrm{ClF}^{*}$

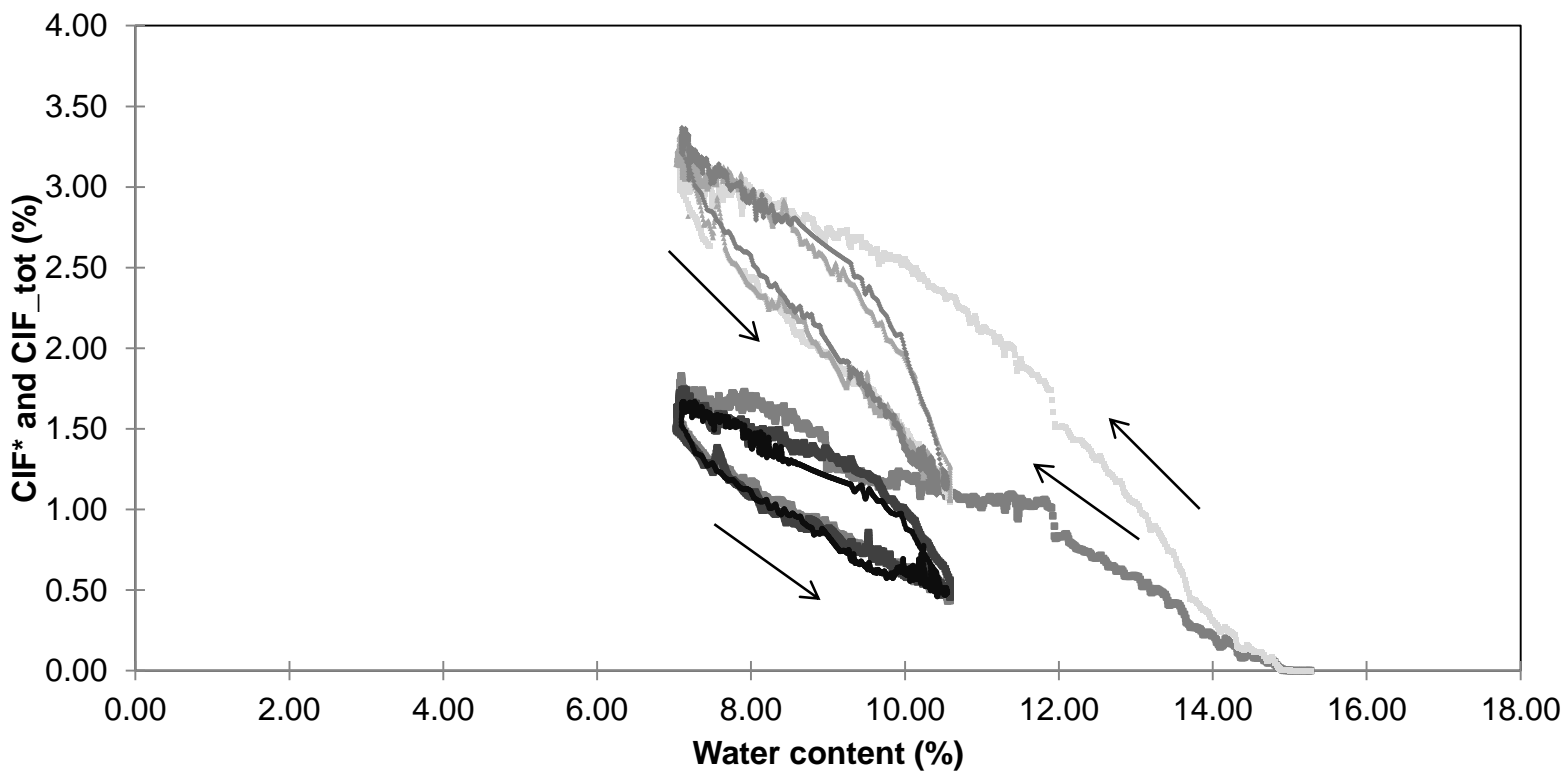

702

$\begin{array}{lll}-1 \text { st cycle }\left(\mathrm{CIF}^{\star}\right) & \text { - 2nd cycle }\left(\mathrm{CIF}^{\star}\right) & \text { - 3rd cycle }\left(\mathrm{CIF}^{\star}\right) \\ \text { 1st cycle }(\mathrm{CIF} \text { _tot }) & \text { 2nd cycle (CIF_tot) } & \text { - 3rd cycle (CIF_tot) }\end{array}$

Fig.15. Comparison between the $\mathrm{CIF}_{\text {tot }}$ and $\mathrm{CIF}^{*}$ 